\title{
Effect of Geometric Parameters on the Behavior of Bolted
} GFRP Pultruded Plates

7 Université de Sherbrooke, Sherbrooke, Quebec, Canada, J1K 2R1

8 E-mail: therese.tajeuna@USherbrooke.ca

$9 \quad{ }^{2}$ Bridge and Tunnel UAE District Manager

10 Parsons Corporation

11 E-mail: Frederic.legeron@parsons.com

$12{ }^{3}$ Assistant Professor

13 Department of Civil Engineering

14 Université de Sherbrooke, Sherbrooke, Quebec, Canada J1K 2R1

15 E-mail: Sebastien.Langlois@USherbrooke.ca

$16 \quad{ }^{4}$ Professor

17 Department of Civil Engineering

18 Université de Sherbrooke, Sherbrooke, Quebec, Canada J1K 2R1

19 E-mail: Pierre.labossière@USherbrooke.ca

$20 \quad{ }^{5}$ Research Engineer

21 Department of Civil Engineering

22 Université de Sherbrooke, Sherbrooke, Quebec, Canada J1K 2R1

23 E-mail: Marc.Demers@ USherbrooke.ca

24

25 *Author to whom all correspondence should be addressed

26

27

28

Paper to be submitted to the Journal of Composites Materials (SAGE) 


\section{ABSTRACT}

31 This paper presents the effect of geometric parameters on the behavior of bolted GFRP

32 pultruded plates for civil engineering applications. After a literature review, results of an 33 experimental analysis investigating the behavior of GFRP-to-steel single-lap bolted

34 connections are presented. Then, a finite element analysis validated by experimental data is 35 used to evaluate the effects of the end-distance, side-distance, gage, pitch and plate 36 properties on the strength and failure mode of the connection. A critical examination of 37 geometric recommendations proposed in design references is presented. Bearing failure 38 caused by contact of the bolt on the GFRP plate is usually defined as the preferred failure 39 mode. With highly orthotropic plate, this type of failure was found to be less likely to occur 40 when loading is applied in the pultruded direction. The investigation showed that the 41 minimum end-distance and pitch-distance recommended by design references usually 42 produce a connection with the maximum capacity. However, it was found that the 43 minimum side-distance recommended by these references does not necessarily lead to the 44 maximum capacity for one-bolt and for two-bolt in a column connections.

45 Keywords: Connection, bolt, pultruded GFRP, single-lap, FE analysis, failure mode, 46 geometric parameters. 


\section{Introduction}

49 This study was initiated in the context of developing a high-strength and low-weight emergency

50 repair solution for damaged railway structures. The use of Glass Fibre Reinforced Polymer

51 (GFRP) pultruded plates was a promising option for this situation, their light weight making

52 them easy to carry on site. Bolting GFRP plates to steel was viewed as a practical way of

53 providing temporary repair work that could also be easy disassemble in the future. In addition,

54 high strength, corrosion resistance, and low maintenance cost would be added benefits if the

55 repair work had to stay in place for an extended period.

56 The main objective of this paper is to provide basic information on the static behavior of

57 bolted joints between GFRP and steel in bridges and other civil engineering structures, to

58 critically examine the geometric recommendations proposed in design references, and to identify

59 optimum geometrical parameters to guarantee the high strength of such connections. In the first

60 part of this paper, a literature review on the connection of GFRP plates is presented. In the

61 second part of the paper, the data presented are complemented by an experimental study of

62 GFRP-to-steel bolted connections performed by the authors. These results are compared to

63 predictions according to a design reference. In the third part of the paper, a finite element (FE)

64 analysis, validated by the experimental results, is used to study how the geometrical parameters

65 of the connection are affecting its strength. In conclusion, optimum geometric parameters beyond

66 which no further increase of the connection strength is observed are identified.

\section{$67 \quad$ Literature review}

68 GFRP pultruded plates are made of E-glass fibres and resin. The pultruded plates are typically a

69 combination of Continuous Strand Roving (CSR) and Continuous Strand Mat (CSM). The

70 roving provides strength in the longitudinal (pultrusion) direction while the mat provides multi- 
71 directional strength. CSM is considered to be isotropic since it contains chopped glass fibres that

72 are randomly oriented in the plane of the mat. The CSR is highly orthotropic and has higher

73 strength than CSM in the longitudinal direction. Therefore, the elastic properties of the plate

74 would depend on the proportion of these two constituents.

75 When connecting GFRP plates with bolts, the basic failure modes shown in Figure 1 can be

76 observed. They are similar to those observed for steel plate connections. Bearing of the bolt

77 produces either crushing in the loading direction (Figure 1a), tension failure through the net-

78 section (Figure 1b) or shear tear-out characterized by two parallel failure paths extending from

79 the bolt-hole to the plate end in the loading direction (Figures 1c and 1d). Another failure mode

80 for FRP pultruded plates is cleavage (Figure 1e), which is characterized by a single fracture line

81 extending from the bolt-hole to the end of the plate. Additional cracks in the net-section may also

82 appear. Failure by crushing is usually ductile and is therefore preferred to the other modes, which

83 are usually brittle.

84 The occurrence of the above failure modes depends on the geometrical parameters shown in

85 Figure 2. These include the number of shear planes $(x)$, the end-distance $(e)$, the side-distance $(s)$,

86 the width $(w)$, the pitch-distance $(p)$ the gage-distance $(g)$, the plate thickness $(t)$, the bolt-hole

87 diameter $\left(d_{h}\right)$, the bolt diameter $(d)$, the number of bolts in the row $(n)$, the number of bolts in the

88 column $(m)$ and the total number of bolt in the connection $(N)$. In a one-bolt or one-column bolts,

$89 s$ is equivalent to $0.5 w$. Recommended values for these geometric parameters can be found in

90 design references such as: ASCE Pre-standard [1], EUROCOMP [2] and CNR-DT 205/2007 [3].

91 Manufacturers such as Strongwell [4], Fiberline Composites [5], and Creative Pultrusion [6] also

92 provide design manuals specific to the use of their products. Table 1 summarizes minimum

93 geometric recommendations for $e, s, p$ and $g$. These recommendations slightly differ from one

94 design reference to another. For example, FRP design standard [1] recommends a minimum 
$95 p / d=4$ while EUROCOMP [2] design manual requires this ratio to be at least 3. ASCE Pre-

96 standard [1] recommends the maximum spacing of consecutive bolts in rows or columns ( $p$ and

$97 \mathrm{~g}$ ) to be 12 times the minimum thickness of FRP material. However, it does not provide

98 recommendations for the edge distances ( $e$ and $s$ ). Other references do not specify the maximum

99 values. Equations to calculate the connection strength corresponding to the failure modes

100 mentioned above can also be found in these design references.

101 Numerous studies of mechanically fastened joints in composite material have been reported in

102 the literature. Most have been conducted for the benefit of aeronautical and automotive industry.

103 An extensive review of several of these publications extending from 1978 to 2007 can be found

104 in Thoppul et al. [8]. For civil engineering application, Mottram and Turvey [9], present a review

105 of publication extending from 1980 to 2001 with regard to the appraisal of existing connections

106 design procedure for plate-to-plate bolted joints in pultruded FRP structural shapes and systems.

107 Girao and Mottram [10] recently reported similar work. In addition to the review of the plate-to-

108 plate bolted joint, [10] also addressed the design procedure of beam-to-column bolted joint.

109 However, this review does not include special topic of environmental effects. A reference and

110 bibliography database on research and development with pultruded FRP shapes and system can

111 be found in [11]. Most connections reported were tested with one bolt [12-33]. A few

112 experimental results with multi-bolt connections can also be found [34-40]. Specimens were

113 mostly loaded in double-lap configuration while few were loaded in single-lap configuration [19,

$11429,30]$. Figure 2(a) presents the geometric parameters as they are defined in this paper and the

115 typical case of single-lap and double-lap configurations. Single-lap connection differs from

116 double-lap configuration in that: double-lap configuration is to some extent symmetric with

117 respect to the center of the inner plate while single-lap configuration is non-symmetric. This non-

118 symmetry causes the inclination of the bolt in the bolt-hole during loading. Because of this 
119 inclination, the bolt contact pressure in the bolt-hole becomes non-uniform through the plate 120 thickness, leading to the out-of-plane deformation of the plate. The present study is limited to 121 bolted connections of Glass Fibre Reinforced Polymer (GFRP) pultruded plates in the context of 122 civil engineering applications. The following literature review focuses on to publications that 123 bring an insight on the effect of geometric parameters as $e / d, s / d, g / d$ or $p / d$ on the connections 124 strength of pultruded GFRP plates with tension loading parallel to the pultruded direction. The 125 test results of Rosner and Rizkalla [13] on one-bolt connections suggest that connection strength 126 and failure mode could be improved by increasing $w / d_{h}$ and $e / d_{h}$ ratios up to a limiting value of 127 5. At this ratio, bearing failure by crushing was the observed mode. Experimental results of 128 Cooper and Turvey [15] reveal that the critical ratio at which bearing failure is observed depends 129 on the clamping of the plates. These critical ratios were found to be $e / d=5$ and $w / d=6$ for lightly 130 torqued and $e / d=6.5$ and $w / d=10$ for fully torqued connections. Experimental results of 131 Ramaskrishna et al. [17] reveal that increasing $w / d$ from 3 to 7 and keeping $e / d=2$ has no 132 significant effect on the strength as shear associated to bearing controls the failure load. Study 133 reported by Wang [23] on a $3.2 \mathrm{~mm}$ thick GFRP pultruded plate loaded in pin bearing condition 134 reveal bearing failure for values of $w / d=4$ and $e / d=1.5$. The results also show no increase in the 135 joint capacity for values of $e / d>3$. From his experimental results performed in single-lap one-bolt 136 joint, Turvey [29] observed a threshold value of $e / d=3$ above which the average ultimate load 137 and strength remain constant for any value of $w / d$. Below this threshold value, the average 138 ultimate load increases with $e / d$ and $w / d$. The author state that because of the effect of bending 139 within the joint, failure modes of the single-lap joints tend to be more complicated than 140 symmetric double-lap joints. Based upon the analysis and observation performed in the 141 experimental investigation, Lee et al [33] recommend to maintain if possible $w / d=5$ and $e / d \geq 3$. 142 For multi-bolted connections, Hassan et al. [37] found that the ultimate capacity and the bearing 
143 strength increased with the ratios of the side-distance-to-pitch $(s / p)$, up to a limiting value of 1.2.

144 Beyond this, no significant increase in the load-carrying capacity was measured. From their

145 finite element analysis performed on multi-column of bolts, Girão Coelho et al. [40] recommend

146 the minimum ratio of $g / d=3$ and $s / d=2.5$. In addition to these geometrical parameters, reported

147 studies also provide information on either the influence of pultruded material orientation [13, 19-

$14820,-23,37]$, the type of fastener [14], washer size [12], hole clearance[16, 27], number of bolts

149 and their arrangement [34, 37], environmental effect [18,21,22,24,25,26,31,39], and degree of

150 orthotropy $[12,34]$. Abd-El-Naby and Hollaway $[12,34]$ show that the failure mode is related to

151 the proportion of CSM and CSR in the plate. Their experimental analysis shows that in plates

152 with higher proportion of CSR than CSM, bearing failure is less likely to occur regardless of the

153 connection length and width.

154 Although other experimental results in multi-bolt connections have been reported, the effect of

155 pitch-distance has not been studied in details. In addition, only few data with single-lap bolted

156 connections have been published. The experimental study on GFRP bolted plates reported in the

157 next section was performed to cover these gaps in data. The investigation was performed on

158 single-lap bolted connections. The results are compared to design strengths calculated using

159 equations available in the ASCE Pre-standard [1]. Then, a FE analysis validated with

160 experimental results is used to investigate the effect of $e, s, p$ and the material properties. The

161 results are used to critically examine the recommendations of design references.

\section{Experimental investigation of single-lap bolted connections}

\section{Overview of the experimental program}

164 Connections of GFRP to steel plates with one bolt or two bolts, in single-lap configuration, were

165 tested. GFRP specimens were cut from $6.35 \mathrm{~mm}$ thick pultruded plates while steel specimens 
were taken from $6.35 \mathrm{~mm}$ thick flat bars. All GFRP pultruded plates were loaded in the

167 longitudinal direction to achieve maximum tensile strength. Connections with one bolt or with

168 two bolts in a column were considered. ASTM A325 bolts with a $12.7 \mathrm{~mm}$ diameter and nominal

169 washer were used. Bolts were tightened at finger tight plus one-half-turn of the nut. Two

170 configurations were tested for one bolt connections. The single-lap configuration S20E30 had

$171 s / d=2$ and $e / d=3$. With these same parameters, three specimens in double-lap configurations

172 (DS20E30) were also tested to investigate the out-of-plane effect on the damage of the GFRP.

173 The configuration $\mathrm{S} 40 \mathrm{E} 40$ had $s / d=4$ and $e / d=4$. For two-bolt connections, two configurations

174 were also tested. The geometric parameters considered were $s / d=4, e / d=4$ and $p / d=3$ for the 175 configuration S40E40P30; $s / d=4, e / d=4$ and $p / d=5$ for the configuration S40E40P50. Three to

176 seven specimens were tested for each configuration for a total 25 tests.

177 Experimental setup and testing of the connections

178 The tests were conducted up to failure of the joint in shear using a $500 \mathrm{kN}$ hydraulic testing

179 machine. As shown in Figure 2(b), the end connections were designed to make the loading axis

180 to coincide with the interface of the two plates so that the bolts were mostly loaded in shear.

181 Specimens were clamped by the grips of the testing machine at both ends. A tensile force was 182 applied at the bottom end while the top end was fixed. The load was applied at the rate of 1

$183 \mathrm{~mm} / \mathrm{min}$ and the load and displacement were recorded by the control system of the testing 184 machine.

\section{Tensile tests of the materials}

186 The GFRP plates were taken from Extren 500 series panels. Extren 500 is manufactured by

187 Strongwell Corporation. According to the manufacturer, it is made of E-glass fibres and 188 polyester resin. It is typically reinforced with $50 \%$ Continuous Strand Roving (CSR) and 189 Continuous Strand Mat (CSM). The roving provides strength in longitudinal (pultrusion) 
190 direction while the mat provides multi-directional strength properties [4]. Steel specimens were 191 cut from 350W flat bars.

Tension tests of GFRP coupons were conducted according to ASTM Standards D3039

193 [41] for longitudinal and transversal tensile strength and ASTM D3518 [42] for in-plane shear 194 strength. For grade 350W steel coupons, ASTM Standard A370 [43] was used. Specimens had 195 uniform width for GFRP and reduced width in the gage length for steel. Strength was measured 196 as specified by the appropriate testing standards. Strain was measured by an axial extensometer. 197 Typical stress-strain curves for steel in tension and GFRP in longitudinal tension, transversal 198 tension and in-plane shear are presented in Figure 3. As it can be observed, GFRP material 199 behaves linearly up to brittle failure. Steel shows an elasto-plastic behaviour. The average 200 measured properties of GFRP coupons are summarized in the first column of Table 2. The 201 properties presented in the other columns of this table are those obtained by other authors and 202 they will be used in the finite element analysis. For steel, the average ultimate tensile strength 203 and average yield strength were approximately $540 \mathrm{MPa}$ and $370 \mathrm{MPa}$ respectively. ASTM 204 A325 bolt was not tested. However, its nominal guaranteed tensile strength is $825 \mathrm{MPa}$ and its 205 nominal shear strength is $495 \mathrm{MPa}$ considering the shear strength equals to 0.6 times the nominal 206 tensile strength [44].

207 Considering the much higher stiffness of steel compared to GFRP, there was no deformation 208 observed on the steel plates and on the A325 steel bolt until GFRP reached failure. Therefore, the 209 observations given in this section are for GFRP plates only.

210 Failure mode of one-bolt single-lap configurations. Figures 4(a) and 4(b) show the typical 211 failure modes of S20E30 and S40E40 respectively. The failure mode of each tested specimen is 212 presented in Table 3. As it can be observed in this table and these figures, the failure mode was 213 not identical within the same configuration. For configuration S20E30 presented on Figure 4(a), 
214 the three typical failure modes were net-section, shear and cleavage. As noted in Table 3,

215 cleavage was the predominant mode within the specimens of this configuration. Cleavage failure

216 was also observed on the three specimens with bolt loaded in double-lap configuration

217 (DS20E30). Suggesting that the varieties of failure mode observed in single-lap could be due to

218 the out-of-plane deformation. On the outer face of some single-lap specimens, washer

219 penetration into the top layer was observed. This damage was not seen in double-lap

220 configuration as the bolt eccentricity was restrained. On configuration S40E40 shear failure was

221 the predominant mode while one specimen (S40E40-4) show cleavage failure. These two typical

222 failure modes are presented in Figure 4(b). For some of these connections, the GFRP plate also

223 present additional cracks either along the main failure line or around the bolt-hole. On the outer

224 face of some GFRP specimens, damage of the top layer due to the out-of-plane deformation was

225 also observed on the free end edge (shear path). This damage was more pronounced on larger

226 specimen than on narrow ones. A typical case of this deformation is shown on specimen

227 S40E40-3 (Figure 4b).

228 Force-displacement curves of one-bolt single-lap connections. Figures 4(c) show the typical

229 force-displacement curves of single-lap S20E30 and S40E40. It is observed that the GFRP plates

230 behave linearly up to approximately $15 \mathrm{kN}$. Then the loads continue to increase, but with a

231 reduced stiffness up to the peak load. The reduction of the stiffness is probably due to the

232 reduction of the clamping pressure between the two plates during loading. The average peak load

233 is observed at approximately $41 \mathrm{kN}$ for $\mathrm{S} 20 \mathrm{E} 30$ and $48 \mathrm{kN}$ for $\mathrm{S} 40 \mathrm{E} 40$ for an average

234 displacement of 2.9 and $2.3 \mathrm{~mm}$ respectively. No relation between failure mode and peak load

235 was observed. After the peak load, the curve suddenly drops down to about 10 to $20 \mathrm{kN}$ for

236 S20E30 and 20 to $30 \mathrm{kN}$ for S40E40 suggesting a partial failure on the GFRP. From this point,

237 the GFRP undergoes a progressive failure. The displacement to which the complete failure 
occurred is unknown because the tests were stopped at this stage as the maximum load was achieved and load was less than $50 \%$ of the maximum value. However, as it can be observed in

240 Figure 4(c), some test results suggest that this displacement can exceed $5 \mathrm{~mm}$. The typical force-

241 displacement curve of double-lap DS20E30 is also presented in Figure 4(c). It is observed that

242 restraining the eccentricity improves the joint stiffness, which is now similar to that of S40E40.

243 However, the displacement at which the peak load occurs is lower compared to S20E30. The

244 average peak load for DS20E30 is $43.4 \mathrm{kN}$. Compared to the average strength in S20E30 (41

$245 \mathrm{kN}$ ), strength reduction associated to out-of-plane deformation is negligible probably due to the

246 short connection length (shear path). More experimental tests are necessary to investigate this

247 effect on connections with wider plate and/or longer shear path.

248 As depicted in Figure 4(c), there is a particularity with the curve of specimens S20E30-1. The

249 linear behaviour of this curve is interrupted at approximately $1 \mathrm{~mm}$ displacement and $20 \mathrm{kN}$

250 force. Here the progression of the load remains insignificant up to $2 \mathrm{~mm}$ displacement. Then, the

251 load increases up to a peak value of $40 \mathrm{kN}$ and a displacement of $3.7 \mathrm{~mm}$. This interruption of 252 the load growth was due to the displacement (slippage) of the bolt in the bolt-hole. This same 253 behavior was also observed on S20E30-3. To prevent this behavior in the specimens tested later, 254 special attention was given to joint tightening to ensure the contact between the bolt-hole and the 255 bolt in the loading direction. In summary, increasing $s / d$ from 2 to 4 and $e / d$ from 3 to 4 , led to a 256 moderately higher connection strength. The joint eccentricity was found to have limited effect on 257 the connection strength when $s / d=2$ and $e / d=3$. However, doubling the shear plane improves the 258 joint stiffness.

259 Failure mode of two-bolt connections. The typical failure mode of two-bolt GFRP-steel single-

260 lap connections is presented in Figures 5. The inner and outer faces of the two bolts connection 261 are presented because the failure mode was not always the same on both faces of the same 
262 specimen. For example, in Figure 5(a), while the inner face of specimen S40E40P30-1 shows 263 signs of net-section failure in the lower row, the outer face in Figure 5(b) shows propagation of 264 cracks around the two bolt-hole (block shear failure). Therefore, it is difficult to characterize this 265 failure mode within the conventional types of failure presented in Figure 1. However, for 266 specimens S40E40P30-2 shows cleavage failure on both faces. Shear failure is observed on 267 specimens S40E40P30-4. However, propagation of cracks in the shear path has different patterns 268 in the inner and the outer faces. On the inner face (Figure 5a), the cracks start from the lower row 269 and propagate towards the top free end of the plate. On the outer face (Figure 5b), the cracks are 270 limited around the two holes. Figures 5(c) and 5(d) present crack damages respectively in the 271 inner and outer face of S40E40P50. Compared to S40E40P30, the failure modes were more 272 consistent on both faces. With S40E40P50, shear failure was the predominant mode. Shear 273 damage was in some cases limited around the bolt-hole (S40E40P50-3), while in other cases 274 (S40E40P50-4) it started at the top row and propagated towards the free end of the plate. Other 275 specimens fail in cleavage (S40E40P50-2). Here, cracks initiated on the side of the lower bolt276 hole and propagated through the top bolt-hole and towards the free end distance. It was also 277 noted that all these configurations show some bearing damage at the lower row. However, no 278 complete bearing failure of the joint was observed.

279 The top layer of all single-lap configurations shows additional crack damages due to the 280 out-of-plane deformation. In two bolt-column, the crack started at the lower row and propagated 281 toward the top row but are interrupted by the compression induced on the washer of the top bolt. 282 This compression forces the top layer of the GFRP plate to develop several cracks between the 283 two bolt-hole as it can be observed on specimens S40E40P30-2, S40E40P50-3 and S40E40P50-4 284 (Figure 5b and 5d). This phenomenon can be observed in Figure 6(a). In one bolt single-lap, 285 these crack damages freely propagated through the shear path as shown in Figure 4(b) for 
specimen S40E40-3. It can also be noted that doubling the number of bolt did not change the

287 failure mode. Shear and cleavage failures are the observed modes in one-bolt and two-bolt 288 connections with $s / d=4$ and $e / d=4$. Observing cleavage failure in such long and wide connections

289 is not surprising as this mode is typical to highly orthotropic composite material.

290 Force-Displacement curves of two bolts connections. In Figure 6, the typical force-

291 displacement curves of S40E40P30 and S40E40P50 are compared. The load history is similar to

292 that observed with one-bolt joints. The peak loads are observed at 75 and $78 \mathrm{kN}$ for S40E40P30

293 and S40E40P50 respectively. Hence, only 4\% gain in the joint capacity was achieved by

294 increasing the pitch. However, displacement at failure increased from an average of $2.1 \mathrm{~mm}$ for

295 S40E40P30 to an average of $3.8 \mathrm{~mm}$ for S40E40P50. The loads sustained by the GFRP plates

296 after the peak load were scattered and vary from $15 \mathrm{kN}$ to $40 \mathrm{kN}$ in both configurations.

297 Therefore, increasing the pitch distance has no significant effect on the GFRP plate carrying

298 capacity. Nevertheless, the joints with higher pitch distance were able to achieve more

299 displacement, therefore a safer behavior. The typical force-displacement curve of S40E40 is also

300 presented on Figure 6. It can be observed that increasing the number of bolts with a constant end-

301 distance and side-distance $(e / d=4$ and $s / d=4)$ from one bolt to two bolts in a column increased the

302 joint capacity by approximately $60 \%$. It is significant that increasing the number of bolts from

303 one to two did not double the load capacity of the GFRP connection. It can also be observed that

304 the peak load of the GFRP plate occurred at approximately the same displacement for S40E40

305 and S40E40P30.

306 In summary, the damage behavior of single-lap connection was difficult to assess. The 307 incompatibility of stiffness between GFRP and steel plates could have been one of the 308 contributing factors of the observed deformations. Using GFRP plate thicker or wider than steel 309 plate could improve the joint stiffness. As carbon composites are stiffer, they might better 
310 address the deformation issues in the composite part of the joints than glass composite. For this

311 study, glass composite was selected instead of carbon composite due to its low cost and

312 availability. Furthermore, with carbon composite, galvanic corrosion could occur and would

313 need to be addressed.

314

\section{Comparison of experimental and predicted results}

316 The ASCE Pre-standard [1] is the most recent design reference for GFRP in civil engineering

317 application. For this analysis, the nominal strength prediction obtained using equations

318 recommended by this ASCE Pre-standard [1] are compared with experimental test results of one-

319 bolt and two-bolt connections. Since only the nominal strength is considered, no resistance factor

320 is used for the calculation of the strength predictions.

\section{Design equations}

322 ASCE Pre-standard [1] provides equations corresponding to each potential failure mode. For net-

323 section failure for a multi-row of bolts, it establishes net-section strength $\left(\mathrm{R}_{\mathrm{nt}}\right)$ presented in

324 Equation 1. The strength per bolt in configuration with one-row of bolt(s) is calculated using

325 Equation 2.

$326 \mathrm{R}_{\mathrm{nt}}=\left[\left(\frac{1}{\left(\frac{\mathrm{w}}{\mathrm{n}}-1\right)}\left(1+\mathrm{C}_{\mathrm{Lt}}\left(\mathrm{S}_{\mathrm{pr}}-1.5 \frac{\mathrm{s}_{\mathrm{pr}}-1}{\mathrm{~s}_{\mathrm{pr}}+1} \theta\right)\right) \mathrm{L}_{\mathrm{br}} \frac{\mathrm{w}}{\mathrm{nd}}\right)+\left(\frac{\left[1+\mathrm{C}_{\mathrm{op}}\left(1+\left(1-1 / \mathrm{s}_{\mathrm{pr}}\right)^{3}\right)\right]\left(1-\mathrm{L}_{\mathrm{br}}\right)}{1-\mathrm{n} \frac{\mathrm{d}_{\mathrm{h}}}{\mathrm{w}}}\right)\right]^{-1}$ w.t. $f_{\mathrm{uLt}}$

$\mathrm{R}_{\mathrm{nt}}=\left[1+\mathrm{C}_{\mathrm{Lt}}\left(\mathrm{S}_{\mathrm{pr}}-1.5 \frac{\mathrm{s}_{\mathrm{pr}}-1}{\mathrm{~s}_{\mathrm{pr}}+1} \theta\right)\right]^{-1}\left(\mathrm{w}-\mathrm{n} \cdot \mathrm{d}_{\mathrm{h}}\right) \mathrm{t} \cdot f_{\mathrm{uLt}}$

328 with:

329

330

$$
\begin{aligned}
& \theta=1.5-0.5\left(\frac{\mathrm{e}}{\mathrm{w}}\right) \text { and } \mathrm{S}_{\mathrm{pr}}=\mathrm{w} / \mathrm{d} \text { for one-bolt per row } \\
& \theta=1.5-0.5\left(\frac{\mathrm{e}}{\mathrm{g}}\right) \text { and } \mathrm{S}_{\mathrm{pr}}=\mathrm{g} / \mathrm{d} \text { for multi-bolt per row }
\end{aligned}
$$

$331 \mathrm{C}_{\mathrm{Lt}}=0.4$ for plate and $\mathrm{C}_{\mathrm{op}}=0.5$ for shape. 
$332 \mathrm{~L}_{\mathrm{br}}$ is the proportion of the connection force taken in bearing at the first bolt row (see Figure 2a).

333 The value of $\mathrm{L}_{\mathrm{br}}$ can be found in [1],

$334 f_{\mathrm{uLt}}$ is the tensile strength in the longitudinal direction of the GFRP plate,

$335 \mathrm{n}$ is the number of bolts in a row.

336 The nominal shear tear-out strength $\left(\mathrm{R}_{\mathrm{sh}}\right)$ per bolt for connection with one-row of bolt(s) is

337 defined in Equation 3. Equation 4 gives the shear tear-out strength per column of bolts for

338 connection with two rows of bolts separated by a pitch $(p)$.

$339 \mathrm{R}_{\mathrm{sh}}=1.4\left(e-\frac{d_{h}}{2}\right) t . f_{\mathrm{ipsh}}$

$340 \quad \mathrm{R}_{\mathrm{sh}}=1.4\left(e-\frac{d_{h}}{2}+p\right) t . f_{\mathrm{ipsh}}$

341 Where $f_{\text {ipsh }}$ is the characteristic in-plane shear strength of the GFRP plate.

342 The bearing strength $\left(\mathrm{R}_{\mathrm{br}}\right)$ per bolt is the product of bearing area to the bearing strength $\left(f_{\mathrm{br}}\right)$ of

343 the material as defined in Equation 5.

$344 \quad \mathrm{R}_{\mathrm{br}}=t . d . f_{\mathrm{br}}$

345 For single bolt centrally positioned with $e / d<4 d$, cleavage strength $\left(\mathrm{R}_{\mathrm{cl}}\right)$ is the lesser of

346 Equations 6 and 7.

$347 \quad \mathrm{R}_{\mathrm{cl}}=0.15\left(\left(2 . s-d_{h}\right) f_{\mathrm{uLt}}+2 . e \cdot f_{\mathrm{ipsh}}\right) \cdot t$

$348 \quad \mathrm{R}_{\mathrm{cl}}=\left(\frac{10}{9}-\frac{4}{9} \frac{d_{h}}{e}\right)^{2} t \cdot d \cdot f_{\mathrm{br}}$

349 Since $f_{\mathrm{br}}$ was not tested in the present experimental study, the ratio of $f_{\mathrm{br}} / f_{\mathrm{uLt}}=1.8$ measured by

350 Rosner and Rizkalla [10] was taken.

351 For a single-row of bolts (with the maximum number of bolts in the row set to three) at uniform

352 gage distance $(g)$, cleavage strength $\left(\mathrm{R}_{\mathrm{cl}}\right)$ is defined as:

353

$$
\mathrm{R}_{\mathrm{cl}}=0.15\left(\left(2 . s+0.5 g-d_{h}\right) f_{\mathrm{uLt}}+2 . e . f_{\mathrm{ipsh}}\right) \cdot t
$$


354 Cleavage strength prediction is not provided for a multi-row of bolts in the ASCE Pre-standard

355 [1]. For connection with multi-row of bolts, ASCE Pre-standard [1] also recommends

356 multiplying the nominal strength of the connection by the ratio of $p / 4 d$ when $p / d<4$.

357 Analysis of the predicted results

358 In Table 4, columns 4 to 8 list the results obtained using Equations 1 to 7 . The average tensile

359 strengths obtained from the tested coupons and reported in Table 2 were used in the calculation.

360 The governing failure load and failure mode are reported in columns 9 and 10. The predicted to 361 experimental ratios are also reported in column 11.

362 For connection S20E30, experimental study produced three types of failure mode: net-section, 363 shear tear-out and cleavage failures. However, among the seven specimens tested for this 364 configuration, failure by cleavage was the predominant mode while only cleavage failure was 365 observed for DS40E30. The ASCE Pre-standard [1] predicts that cleavage governs design, which

366 is consistent with some experimental specimens. However, the predicted strength governed by 367 Equation 6 was underestimated by $53 \%$ to 55\%. For connection S40E40, failure by shear was the 368 predominant mode observed experimentally. The ASCE Pre-standard [1] predicts that failure by 369 shear governs the design. However, it underestimates the strength by $15 \%$ compared to 370 experimental tested results. It is important to note that the ASCE Pre-standard [1] recommends 371 that cleavage should not be considered for connection with $e / d \geq 4$. However, experimental results 372 reveal that this failure mode is possible for $e / d=4$.

373 The ASCE Pre-standard [1] predicts net-section failure for S40E40P30 and S40E40P50. It was 374 rather shear tear-out and cleavage that were observed experimentally for S40E40P30. Shear tear375 out was also the predominant failure mode observed experimentally for S40E40P50. Therefore, 376 the predicted failure mode is not consistent with experimental observations. While the strength 377 prediction of S40E40P50 is only $18 \%$ below the experimental failure load, that of S40E40P30 is 
underestimated by $36 \%$. For S40E40P30, this larger underestimation is due to the requirement of 379 multiplying the net-section connection strength by the ratio of $p / 4 d$ when $p$ is less than the 380 required minimum. Such recommendation significantly reduced the connection strength 381 prediction even though it was observed experimentally that the pitch had limited effect on the 382 failure load. ASCE Pre-standard [1] does not provide an equation of cleavage strength for multi383 row of bolts. However, in experimental section, some specimens of S40E40P30 and S40E04P50 384 show failure by cleavage. Therefore, it could be useful to define an equation capable of 385 predicting this failure mode for a multi-row of bolts.

386 More data are required to better understand the relationship between the different geometric 387 parameters and the connection strength. Finite element approach will be used to extend such data.

\section{Finite element analysis}

\section{Overview of the finite element analysis}

390 Through FE analysis, this section aims to investigate the effects of the end-distance $(e)$, the side391 distance $(s)$ and the pitch $(p)$ on the connection strength. A two-dimensional (2D) finite element 392 model was developed with the commercial software ADINA 8.7.3. The analysis started with a 393 validation study based on experimental results described above and also with the data of some 394 papers discussed above $[10,17]$. The properties shown in Table 2 were used for this part of the 395 study. This validation was followed by a parametric simulation where the effect of geometrical 396 parameters for one-bolt connections and two-bolt connections aligned parallel to the loading 397 direction, was investigated. The ratio were $1 \leq e / d \leq 5$ and $1.5 \leq e / d \leq 5$. The pitch-distance $(p / d=2$, 398 3, 4 and 5) for two-bolt parallel to the loading direction (two-bolt in a column) were also 399 investigated. In the parametric study, two types of GFRP plates were studied: one with the ratio 400 of $\mathrm{E}_{\mathrm{Tt}} / \mathrm{E}_{\mathrm{Lt}}=0.2$ using the properties of the plates in the current study; the other with the ratio of $401 \mathrm{E}_{\mathrm{Tt}} / \mathrm{E}_{\mathrm{Lt}}=08$ using the properties of the plates reported by [17]. The interest the two types of plates 
402 is the relative proportion of CSR and CSM. The model with $\mathrm{E}_{\mathrm{Tt}} / \mathrm{E}_{\mathrm{Lt}}=0.2$ represents a highly

403 orthotropic material. It achieves higher strength in the pultruded direction than in the transversal

404 direction. On the other hand, with a ratio of $\mathrm{E}_{\mathrm{Tt}} / \mathrm{E}_{\mathrm{Lt}}=0.8$, the relative proportion of CSM and

405 CSR leads to quasi-isotropic plate.

406 Analysis assumptions

407 This study was limited to the evaluation of joint strength and failure mode for GFRP with 408 loading parallel to the pultruded direction. In the experimental study of GFRP-to-steel 409 connection, failure of the joint was due to the GFRP fracture. Therefore, only the GFRP plate 410 was modelled in the finite element (FE) analysis. Figure 7(a) presents the typical 2D model used 411 for this analysis. For model validation, all configurations tested in the experimental program 412 were analysed. Additional configurations reported in others papers $[10 ; 17]$ were also used. Their 413 material properties are presented in Table 2 while details of chosen configurations are presented 414 in Table 5. In the static environment of ADINA, the GFRP plate was modelled as a 2D solid with 415 a quadrilateral element. These elements haves nine nodes per element and six degrees of freedom 416 per node. The mesh density is shown in Figure 7(a). Each element edge length was 417 approximatively equal to $2 \mathrm{~mm}$. The mesh density was refined around the bolt-hole. In a square 418 refined mesh area, the length ratio of the element edges (last element/first element) was equal to 419 0.2. It was verified that further reducing the mesh size does not influence the stress distribution 420 in the model. The GFRP plate was modelled as a plastic orthotropic material. The anisotropy 421 parameters were determined from yield stresses. The input yield stresses were taken as the 422 ultimate tensile strengths of the material and the input plastic strain was taken as a material 423 longitudinal tensile strain. Contact between the bolt and the plate was modelled by a contact 424 feature available in ADINA. To reduce the computation time, the bolt was modelled as a rigid 425 half cylinder. The contact interface was generated as a pair of surface elements. On this interface, 
the bolt was defined as a target surface and the bolt-hole elements as a contactor surface. This

427 assumption was based on the fact that the elastic modulus of the steel bolt is greater than that of

428 GFRP plate. Due to the use of contact elements, no boundary condition was applied on this

429 interface. For all configurations, the length L presented in Figure 7(a) was always constant and

430 equal to $127 \mathrm{~mm}$. A uniform pressure was applied in the longitudinal Z-axis on the far end plate

431 edge. The external load was applied incrementally on the structure. Once the GFRP plate reached

432 the input strain, the model diverged. The recorded peak load was taken as the strength of the

433 connection.

\section{$434 \quad$ Validation of the finite element model}

435 Figures 7(b) to 7(g) present the post-processing Hill effective stress distribution of the FE model.

436 Based on the stress distribution along a given failure path of the model, the joint failure mode

437 was defined. For example, for shear tear-out failure presented in Figure 7(b) and 7(c), excessive

438 stresses are developed between the sides of the bolt-hole and propagate towards the free end

439 edge of the plate. For net-section failure, excessive stresses are developed across the centerline of

440 the bolt-hole in the net-section path (Figure 7d). A typical bearing failure is presented in Figure

$4417(\mathrm{e})$; stresses are limited ahead of the bolt-hole in the bearing path and barely reach the free end

442 edge of the plate. Cleavage failure is characterized by excessive stresses ahead of the bolt-hole

443 (Figure 7f) In addition, excessive stresses also develop from the free end edge of the plate

444 towards the bolt-hole in the loading direction. In Table 5, the ultimate loads $\left(\mathrm{P}_{\mathrm{FE}}\right)$ and failure

445 modes obtained from FE analysis of one and two bolts connections are compared to the average

446 experimental failure loads. It can be observed that the FE results are in very good agreement with

447 experimental results. In general, the FE failure loads are slightly conservative. All ratios of

448 predicted to experimental results are within $8 \%$ difference. The observed FE failure modes were

449 also quite consistent with the experimental failure modes. In Figure 8, the typical force- 
450 displacement curves obtained in the FE analysis are compared to that of experimental results.

451 Here also, it can be seen that the force-displacement history are quite consistent with that of 452 experimental curves up to the peak load at which the FE model stops.

\section{Parametric simulation and analysis of the results}

454 Following the satisfactory agreement between FE model and experimental results, a parametric 455 study was carried out. The results obtained from the parametric simulation are presented in Table

456 6. For connections with one or two bolts, the FE results were used to define the boundaries of 457 predicted failure modes and are shown in Figure 9 by dashed lines. These boundaries are 458 presented in Figure 9(a) for one-bolt connections of GFRP plates with $\mathrm{E}_{\mathrm{Tt}} / \mathrm{E}_{\mathrm{Lt}}=0.2$ and in Figure 459 9(b) for those with $\mathrm{E}_{\mathrm{Tt}} / \mathrm{E}_{\mathrm{Lt}}=0.8$. The boundaries of predicted failure modes according to ASCE 460 Pre-standard [1] were also identified and are shown by the lines in Figure 9(c) for connections of 461 a GFRP plate with $E_{T t} / E_{L t}=0.2$, and in Figure $9(d)$ for $E_{T t} / E_{L t}=0.8$. Failure modes from our 462 experimental study and those reported in reference papers are listed in Table 7. They are 463 represented by symbols in Figure 9 where they are regrouped for $\mathrm{E}_{\mathrm{T} t} / \mathrm{E}_{\mathrm{Lt}} \leq 0.3$ in Figures $9(\mathrm{a})$ and $4649(\mathrm{c})$ or $\mathrm{E}_{\mathrm{Tt}} / \mathrm{E}_{\mathrm{Lt}} \geq 0.7$ in Figures $9(\mathrm{~b})$ and $9(\mathrm{~d})$. Failure loads from Table 6 are reported in Figures 465 10(a) and 10(b) for various geometrical parameters of one-bolt connections. The predicted 466 failure loads using ASCE Pre-standard [1] for the minimum recommended side-distance are also 467 shown by the dotted line. The numbers in parenthesis in Figure 10 identify the equation that 468 governs the design according to [1] with the minimum recommended side-distance $(s / d=1.5)$. For 469 two-bolt connections, information similar to Figure 9 and 10 is provided in Figures 11 and 12.

\section{Effects of geometric parameters in one-bolt connections}

471 For one-bolt connection, FE results in Figures 9(a) and 9(b) identified three failure zones: 472 cleavage, shear and net-section for connections with highly orthotropic GFRP plates and 473 cleavage, net-section and bearing for those with quasi-isotropic GFRP plates. On the other hand, 
474 ASCE Prestandard [1] identifies the fours failure zones for each material. The experimental data

475 points presented in Figure 9(b) and 9(c) show that FE analysis provided better predictions than 476 [1] for connections with quasi-isotropic GFRP plates. However, due to the limitted number of 477 data point, it is difficult to conclude which one of the FE analysis or the ASCE Pre-standard 478 equations provide the best predictions for these failure modes in the case of a highly orthotropic 479 plate. Therefore, more experimental data points would be needed for this material.

480 The failure loads predicted by FE analysis for one-bolt connections are presented in Table 481 6. For connections with $\mathrm{E}_{\mathrm{T} t} / \mathrm{E}_{\mathrm{Lt}}=0.2$ and $\mathrm{E}_{\mathrm{T} t} / \mathrm{E}_{\mathrm{Lt}}=0.8$, it can be observed that for $s / d \leq 1.5$, there is 482 no significant gain in failure load when $e / d>4$. Similarly, for $s / d \unrhd 2$, there is no increase in failure 483 load when $e / d>4$. It is useful to compare this observation with ASCE Pre-standard [1] or 484 manufacturer [4,6] recommendations. For one-bolt connection, ASCE Pre-standard [1] 485 recommends the minimum values of $e / d=4$ and $s / d=1.5$. This appears to be a conservative 486 geometrical value for the end-distance since the FE analysis shows that approximately the same 487 failure load can be attained for $s / d=1.5$ and $e / d=3$. On the other hand, the manufacturers 488 recommend a minimum combination of $e / d=3$ and $s / d=2$. For these parameters, the FE predicted 489 load is approximately $55 \%$ higher than the one corresponding to the recommendation of ASCE 490 Pre-standard [1] for both materials.

491 All FE values associated to one-bolt connections are illustrated in Figures 10(a) and 492 10(b). The prediction of ASCE Pre-standard [1] for the minimum recommended side-distance $493 s / d=1.5$ is identified by the dotted line in these figures. When comparing the FE predictions and 494 ASCE Pre-standard [1] predictions for $s / d=1.5$ (Figure 10a), the strengths predicted by [1] 495 governed by cleavage (equation 6) are approximately 50\% lower than FE analysis that also 496 predcits cleavage for $-e / d=2$ and $e / d=3$. However, for all other values of $e / d$, the loads predicted 497 by [1] are consistent with the FE predicted loads. For connections of quasi-isotropic GFRP plates 
presented in Figure 10(b), the failure loads predicted by [1] for $s / d=1.5$ and varying values of $e / d$

499 are all quite consitent with the FE predicted loads. Although predicted loads with ASCE Pre-

500 standard [1] are governed by the same design equations as for highly orthotropic plates, cleavage

501 strength predicted using Equation 6 seems to provide a better prediction for quasi-isotropic than

502 for highly orthotropic plates.

\section{Effects of geometric parameters in two-bolt connections}

504 For two-bolt connection, FE results in Figures 9(a) and 9(b) identifies three failure zones:

505 cleavage, shear and net-section for connections with highly orthotropic GFRP plates. For 506 connections with quasi-isotropic GFRP plates, only two failure zones: cleavage and net-section 507 are identified. On the other hand, ASCE Prestandard [1] identifies only shear and cleavage zones 508 for connections with highly orthotropic GFRP plates and net-section failure is the only occuring 509 mode for those with quasi-isotropic GFRP plates. The experimental data points presented in 510 Figure 11(b) and 11(d) show that FE analysis provided a better predictions than [1] for 511 connections with quasi-isotropic GFRP plates. However, the limit number of data points for 512 highly orthotropic plate is not sufficient to conclude on the actual predictions. Therefore, more 513 experimental data points would be needed for this material.

514 The failures loads predicted by FE analysis for two-bolt connections are presented in

515 Table 6. For connections of highly orthotropic plates with $\mathrm{E}_{\mathrm{Tt}} / \mathrm{E}_{\mathrm{Lt}}=0.2$, it can be observed that for $516 s / d=1.5$, there is no significant gain in failure load when $e / d>2$. Similarly, for $s / d \geq 2$, there is no 517 significant increase in failure load when $e / d \geq 4$. For connections of quasi-isotropic plates with $518 \mathrm{E}_{\mathrm{Tt}} / \mathrm{E}_{\mathrm{Lt}}=0.8$, no significant increase in the failure load is observed when $e / d \geq 2$ and $s / d \leq 3$. Above $519 s / d>3$, the strength increases with $e / d$ up to a ratio of 3 . It is useful to compare this observation 520 with ASCE Pre-standard [1] or manufacturer [4,6] recommendations. For two-bolt connection, 521 ASCE Pre-standard [1] recommends the minimum values of $e / d=2, s / d=1.5$ and $p / d=4$. On the 
522 other hand, the manufacturers recommend a minimum combination of $e / d=3, s / d=2$ and $p / d=3$.

523 The recommendation of the manufacturer leads to a connection strength approximately $52 \%$ and $52457 \%$ higher than that corresponding to the ASCE Pre-standard [1] minimum values for 525 connections with $\mathrm{E}_{\mathrm{Tt}} / \mathrm{E}_{\mathrm{Lt}}=0.2$ and $\mathrm{E}_{\mathrm{Tt}} / \mathrm{E}_{\mathrm{Lt}}=0.8$ respectively. It is interresting to note that, for all 526 values associated to two-bolt connections in Table 6 increasing $p / d$ above 3 has little effect on 527 the connection failure load.

528 The FE values associated to two-bolt connections are also illustrated in Figure 12(a) and 52912 (b) for the recommended value of $e / d=2$ with various ratios of $s / d$ and $p / d$. The prediction of 530 ASCE Pre-standard [1] for the minimum recommended side-distance $s / d=1.5$ is identified by the 531 dotted line in these figures. When comparing the FE predictions and ASCE Pre-standard [1] 532 predictions for $s / d=1.5$, the difference in prediction is significant for values of $p / d<4$ for both 533 types of plates. For these geometric parameters, the design values are governed by net-section 534 failure (Equation 1) which produces the predicted strengths approximately 60\% lower than FE 535 prediction for $p / d=2$ and $38 \%$ for $p / d=3$ for highly orthotropic plates. For quasi-isotropic plates 536 this difference is $38 \%$ for $p / d=2$ and $26 \%$ for $p / d=3$. However, when $p / d \geq 4$, the results predicted 537 by [1] are quite consistent with FE results. In that case, the maximum difference between the 538 predicted loads and the FE loads is nearly $17 \%$ for connections with $\mathrm{E}_{\mathrm{Tt}} / \mathrm{E}_{\mathrm{Lt}}=0.2$ while it does not 539 exceed $16 \%$ for connections with $\mathrm{E}_{\mathrm{Tt}} / \mathrm{E}_{\mathrm{Lt}}=0.8$. This larger difference for values of $p / d<4$ is due to 540 the recommendation of ASCE Pre-standard [1] to reduce the predicted strength of connection 541 with $p / d<4$ to the ratio of $p / 4 d$.

\section{CONCLUSIONS}


544 The aim of this paper was to investigate the effect of geometric parameters and material

545 properties on the behavior of GFRP-to-steel bolted connections. An experimental study on a

546 GFRP pultruded plate connected to a steel plate was performed. The effects of increasing the

547 side-distance, the end-distance, the pitch, and the number of bolts in the joint were discussed.

548 The experimental results were compared to the strength calculated from ASCE Pre-standard [1].

549 Finally, FE analysis along with experimental data, were used to evaluate the failure load and

550 failure mode of other geometric parameters. It was found that:

551 - The parametric study showed that the failure mode can be better predicted with the FE

552 model than with ASCE Pre-standard [1] for both highly orthotropic and quasi-isotropic 553 materials.

554 - For one-bolt connection, the experimental results obtained in the present study show that 555 increasing $s / d$ from 2 to 4 and $e / d$ from 3 to 4 , lead to a moderately higher strength and an 556 improved behavior of the joint at failure. Bearing failure was not observed due to the use 557 of highly orthotropic material. Experimental data along with FE parametric analysis show that this failure mode would happen for GFRP plate with quasi-isotropic material.

- For two bolt in a column, the experimental results show that increasing the pitch distance from 3 to 5 provides no significant increase of capacity. Nevertheless, the connections with higher pitch distance were able to achieve more displacement, therefore a safer behavior. The experimental data and FE analysis reveal that pure bearing failure is not likely to occur. For connections with highly orthotropic plate, shear or cleavage were found to be the predominant failure modes. For connections with quasi-isotropic plates, cleavage was observed for short end-distance and net-section failure was predominant for $e / d>2$. 
- The out-of-plane deformation was found to have limited effect on the strength of the tested connections (S20E30). Failure modes in single-lap were difficult to assess as a

\section{RECOMMENDATION}

576 Based on the results of this work, recommendations to improve the ASCE Pre-standard [1] are

577 formulated as follows.

578 - The values of $s / d=2$ and $e / d=3$ should be considered as a minimum values for GFRP bolted connections as they were found to provide higher strength than the strength obtained with the values recommended by ASCE Pre-standard [1].

- The recommendation of ASCE Pre-standard [1] to multiply the connection strength by the ratio of $p / 4 d$ when $p$ is less than the required minimum could significantly underestimate the strength of the connection for both highly orthotropic and quasiisotropic materials. Therefore, further consideration should be given to this aspect.

- More experimental data especially for connections with highly orthotropic GFRP plate $\left(\mathrm{E}_{\mathrm{T} t} / \mathrm{E}_{\mathrm{Lt}} \leq 0.3\right)$ are required to validate some of the parametric observations. For quasiisotropic GFRP plate $\left(\mathrm{E}_{\mathrm{Tt}} / \mathrm{E}_{\mathrm{Lt}} \geq 0.7\right)$, additional experimental data will be necessary to define the bearing failure mode zone.

- More experimental analyses are necessary to study the effect of out-of-plane deformation on multi-row bolts. 
592 The financial support provided by Natural Science and Engineering Research Council of Canada

593 (NSERC) is well appreciated. Special thanks to the manufacturer Strongwell Corporation for 594 providing GFRP plates.

\section{REFERENCES}

[1] ASCE. Pre-Standard for Load and Resistance Factor Design (LRFD) of Pultruded Reinforced Polymer structure (Final). USA, 2010, pp.67-84.

[2] Clarke J.L. EUROCOMP Design Code and Handbook. London. E \& FN Spon. First Edition, 1996, ISBN 0419194509

[3] CNR-DT 205/2007. Guide for the Design and Construction of Structures Made of FRP Pultruded Elements. Advisory Committee on Technical Recommendation for Construction. http://www.cnr.it/documenti/norme/IstruzioniCNR_DT205_2007_eng.pdf

[4] Strongwell. Extren Design Manual, Bristol, VA, 2002.

[5] Fiberline Composites. The Fibreline Design Manual. Denmark, 2003.

[6] Creative Pultrusions. The Pultex Pultrusion Global Design Manual. Alum Bank, PA, 2001.

[7] Bank, L.C. Composite for Construction Structural Design with FRP materials. John Wiley \& Sons, Inc. USA, 2006.

[8] Thoppul S.D., Finegan J. and Gibson R.F. Mechanics of mechanically fastened joints in polymer-matrix composite structures - A review, Composites Science and Technology 2008; 69:301-329.

[9] Mottram JT. and Turvey GJ. Physical test data for the appraisal of design prcedures for bolted joints in pultruded FRP structural shapes and systems, Progress in Structural Engineerong and Materials 2003; 5(4): 195-222.

[10] Girao Coelho AM. and Mottram JT. A review of the behaviour and analysis of bolted connections and joints in pultruded fibre reinforced polymers, Materials and Design, 2015; 74: 86-107.

[11] Mottram JT. Reference and bibliography database on research and development with pultruded fibre reinforced polymer shapes and systems, 2014. http://www2.warwick.ac.uk/fac/sci/eng/staff/jtm/prfp_latest.pdf

[12] Abd-El-Naby S.F.M. and Hollaway L. The experimental behaviour of bolted joints in pultruded glass/polyester material. Part 1: Single-bolt joints. Composites 1993a, 24(7): 531538.

[13] Rosner C.N. and Rizkalla S.H. Bolted connections for fibre-reinforced composite structural members: Experimental program. Journal of Materials in Civil Engineering, ASCE 1995, 7(4): 223-231.

[14] Erki M.A. Bolted glass-fibre-reinforced plastic joints. Canadian Journal of Civil Engineering 1995; 22: 736-744.

[15] Cooper C. and Turvey G.J. Effects of joint geometry and bolt torque on the structural performance of single bolt tension joints in pultruded GRP sheet material. Composite Structures, 1995, 32(1-4): 217-226.

[16] Yuan, R.L., Liu, C.J., and Daley, T. Study of mechanical connection for GFRP laminated structures, Proc. 2nd International Conference on Advanced Composite Materials in Bridges 
and Structures ACMBS-2, The Canadian Society for Civil Engineers, Whistler, 1996, 951958.

[17] Ramaskrishna S. Hamada H. and Nishiwaki M. Bolted joints of pultruded sandwich composite laminates. Composite Structures 1995; 32: 227-235

[18] Yuan, R.L. and Weyant, S.E. The effect of environmental exposure of the behavior of pultruded mechanical connections, in Proc. Annual Conf. Composite Institute, SPI, 1997, Session 14-F.

[19] Turvey, G.J. Single-bolt tension joint tests on pultruded GRP plate: effects of tension direction relative to pultrusion direction, Compos. Struct., 1998, 42(4), 341-351. DOI: 10.1016/S0263-8223(98)00079-8

[20] Yuan, R.L., and Liu, C.J. "Experimental characterization of FRP mechanical connections", Proc. 3rd International Conference on Advanced Composite Materials in Bridges and Structures ACMBS-3, The Canadian Society for Civil Engineers Montreal, 2000, 103-110.

[21] Turvey, G.J. and Wang, P. Single-bolt tension joints in pultruded GRP material Effect of temperature on failure loads and strengths and joint efficiency, in Proc. Conf. on Strain Measurement in the 21st Century, British Society for Strain Measurement, 2001, 20-23.

[22] Turvey, G.J. and Wang, P., 'Effect of temperature on the structural integrity of bolted joints in pultrusions,' in Proc. Inter. Conf. on Composites in Construction - CCC2001, A.A. Balkema Publishers, (Swets \& Zeitlinger) Lisse, 2001, 171-176.

[23] Wang, Y. Bearing behavior of joints in pultruded composites, J. Compos. Mater., 36(18), 2002, 2199-2216. DOI: 10.1177/0021998302036018535

[24] Turvey, G.J. and Wang, P. Single-bolt tension joints in pultruded GRP plate - effects of elevated temperature on failure loads, failure modes, load orientation and joint efficiency, in Proc. Joining Plastics 2006, Rapra Conf. Proc., 2006, Paper No. 9.

[25] Turvey, G.J. and Wang, P., Thermal preconditioning study for bolted tension joints in pultruded GRP plate, Composite Structures, 77 4, 2007, 509-513.

[26] Turvey, G.J. and Wang, P., Failure of pultruded GRP single-bolt tension joints under hotwet conditions, Composite Structures, 77 4, 2007, 514-520.

[27] Turvey, G.J. and Wang, P., Effect of hole clearance on bolt loads in pultruded GRP tension joints, in Proc. 16th Inter. Conf. on Composite Materials (ICCM-16), July 2007, Kyoyto.

[28] Turvey G.J. and Wang, P., Failure of pultruded GRP bolted joints: a Taguchi analysis, Engineering and Computational Mechanics, 162 3, 2009, $155-166$

[29] Turvey, G.J., Failure of single-lap single-bolt tension joints in pultruded glass fibre reinforced plate, Proc. 6th International Conference on Composites in Construction Engineering (CICE), Rome, 2012, Paper 08.089.

[30] Turvey, G.J. and Godé, J. An experimental investigation of the tensile behaviour of singlelap bolted joints in pultruded GFRP plate, in Proc. of FRP Bridge Conf., London, Net Composites, Chesterfield, 2012, 77-91. CD-ROM

[31] Zafari, B. and Mottram, J.T., Effect of hot-wet aging on the pin-bearing strength of a pultruded material with polyester matrix, J. of Composites for Construction, 16 3, 2012, 340352.

[32] Turvey, G.J., Ultimate loads, strength, extensions and strains of pultruded GFRP single-lap, single-bolt tension joints, in Proc. 6th Inter. Conf. on Advanced Composites in Construction, Net Composites Ltd., Chesterfield, UK, 2013, 373-382.

[33] Lee, Y-G., Choi, E. and Yoon, S-J, Effect of geometric parameters on the mechanical behavior of PFRP single bolted connection, Composites Part B -Engineering, 75, 2015, 1-10. 
682

683

684

685

686

687

688

689

690

691

692

693

694

695

696

697

698

699

700

701

702

703

704

705

706

707

[34] Abd-El-Naby S.F.M. and Hollaway L. The experimental behaviour of bolted joints in pultruded glass/polyester material. Part 2: two-bolt joints. Composites 1993b, 24(7): 539546.

[35] Prabhakaran R., Devara S. and Razzaq Z. The effect of fiber orientation angle on the unnotched, open hole, and pin-loaded strength of a pultruded composite. In: Proceeding of the $51^{\text {st }}$ Annual Conference of the composite Inst. Society of the Plastic Industry, Washington DC; 1996; 1-15.

[36] Prabhakaran R., Razzaq Z. and Devara S. Load and resistance factor design (LRFD) approach for bolted joints in pultruded composites. Composites Part B: Engineering 1996; 27: $351-360$.

[37] Hassan N.K., Mohamedien M.A. and Rizkalla S.H. Multibolted joints for GFRP structural members. Journal of Composites for Construction, ASCE 1997; 1(1): 3-6.

[38] Prabhakaran, R., and Robertson, J., 1998, An experimental investigation of load-sharing in a multi-bolt pultruded composite joint, Proc. 2nd International Conference on Composites in Infrastructure ICCI, H. Saadatmanesh, M.R. Ehsani (eds.), Tucson, pp. 355-368.

[39] Turvey, G.J. and Wang P., Environmental effects on the failure of GRP multi-bolt joints, Structures and Buildings, 162 4, 2009, 275-287.

[40] Girão Coelho, A.M., Mottram J.T. and Harries, K.A., Bolted connections of pultruded GFRP: Implications of geometric characteristics on net section failure, Composite Structures, 131, (2015), 878-884. http://dx.doi.org/10.1016/j.compstruct.2015.06.048

[41] ASTM D3039/D3039M-00:2006. Standard Test Method for Tensile Properties of PolymerMatrix Composite Materials. Vol. 15.03. Composite Materials. ASTM International West Conshohocken, PA.

[42] ASTM D3518/D3518M-94:2007. Standard Test Method for In-Plane Shear Response of Polymer Matrix Composite Materials by Tensile Test of a $\pm 45^{\circ}$ Laminate-Matrix. Vol. 15.03. Composite Materials. ASTM International. West Conshohocken, PA.

[43] ASTM A370-12:2005. Standard Test Methods and Definitions for Mechanical Testing of Steel Products Vol. 01.03. ASTM International. West Conshohocken, PA.

[44] Kulak, G. L., Adams, P.F., Gilmor, M.I. Limit States Design in Structural Steel. Canadian Institute of Steel Construction, $5^{\text {th }}$ edition, 1998.

\section{List of Figures}

Figure 1. Failure modes: (a) Bearing, (b) net-section, (c) shear tear-out, (d) Block shear (e) cleavage

Figure 2. (a) Typical joint geometric parameters, (b) Test set-up

Figure 3. Stress-strain relationships of the materials

Figure 4. Typical failure damages of GFRP (a) Inner face S20E30, (b) Outer face S40E40, (c)

Typical force-displacement curves of S20E30 compared to S40E40 and DS20E30 
723 Figure 5. Failure damages of GFRP (a) Inner face of S40E40P30 (b) Outer face of S40E40P30,

724 (c) Inner face of S40E40P50 (d) Outer face of S40E40P50.

725 Figure 6. (a) Out-of-plane deformation of a two bolt-column, (b) Typical force-displacement 726 curves of S40E40P30 compared to S40E40P50 and S40E40.

727 Figure 7. (a) Typical 2D model, Post-processing failure modes: (b) bearing, (c) net-section, (d) 728 and (e) shear tear-out, (f) cleavage.

729 Figure 8. Typical force-displacement curves of the experimental compared to finite element 730 models: (a) S20E30, (b) S40E40, (c) S40E40P3, (d) S40E40P50.

731 Figure 9. Effect of $e / d$ and $s / d$ on failure modes for one-bolt: (a) FE and Exp. failure modes for 732 highly orthotropic plates; (b) FE and Exp. failure modes for quasi-isotropic plates; (c) [1] and 733 Exp. failure modes for highly orthotropic plates; (d) [1] and Exp. failure modes for quasi734 isotropic plates;

735 Figure 10. Effect of $e / d$ and $s / d$ on joint strength for one-bolt: (a) FE failure loads for highly 736 orthotropic plates; (b) FE failure loads for quasi-isotropic plates

737 Figure 11. Effect of geometric parameters on failure modes for two-bolt: (a) FE and Exp. failure 738 modes for highly orthotropic plates; (b) FE and Exp. failure modes for quasi-isotropic plates; (c) 739 [1] and Exp. failure modes for highly orthotropic plates; (d) [1] and Exp. failure modes for 740 quasi-isotropic plates

741 Figure 12. Effect of geometric parameters on joint strength for two-bolt: (a) FE failure loads for 742 highly orthotropic plates; (b) FE failure loads for quasi-isotropic plates

\section{List of Tables}

746 Table 1. Minimum geometric requirements from design manuals ( $d$ : diameter of the bolt, $d_{h}$ : 
747 bolt-hole)

748 Table 2. Mechanical properties of the materials

749 Table 3. Tests results of bolted joints

750 Table 4. Comparison of experimental to predicted results

751 Table 5 Model validation

752 Table 6. FE results: failure load $(\mathrm{kN}) /$ failure mode

753 Table 7. Experimental failure modes

754 


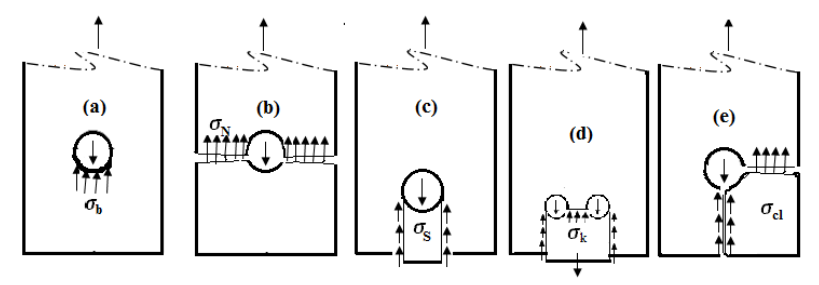

Figure 1. Failure modes: (a) Bearing, (b) net-section, (c) shear tear-out, (d) Block shear (e) cleavage 

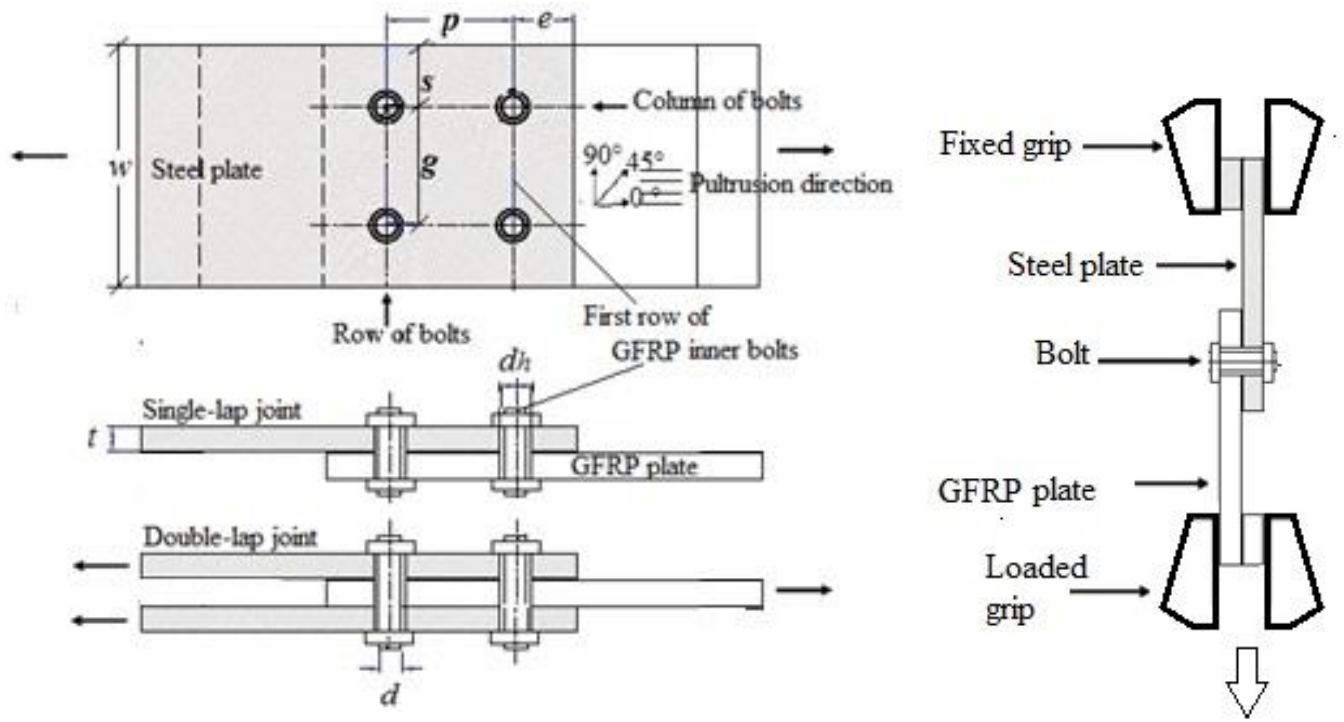

Figure 2. (a) Typical joint geometric parameters, (b) Test set-up 


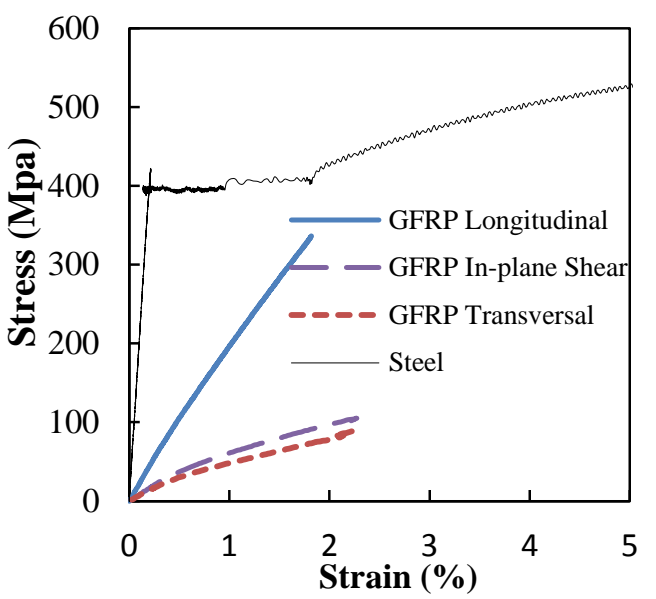

Figure 3. Stress-strain relationships of the 763 materials 
(a)



(b)

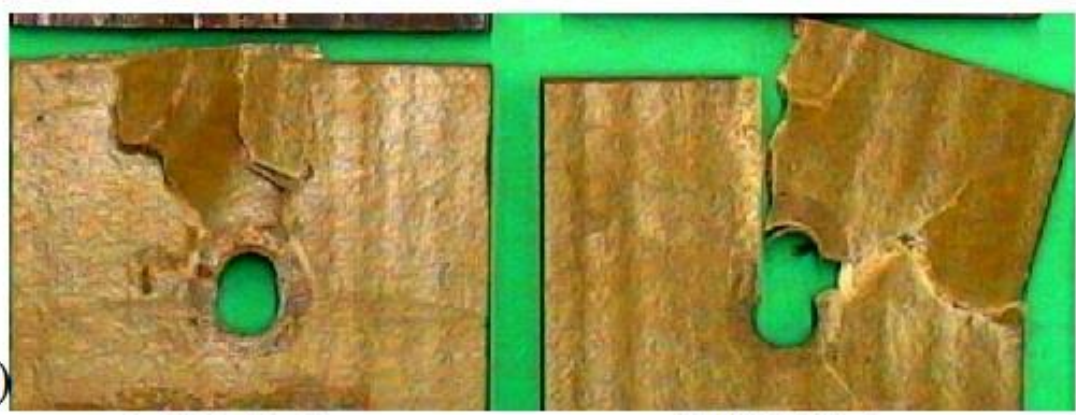

S40E40-3

S40E40-4

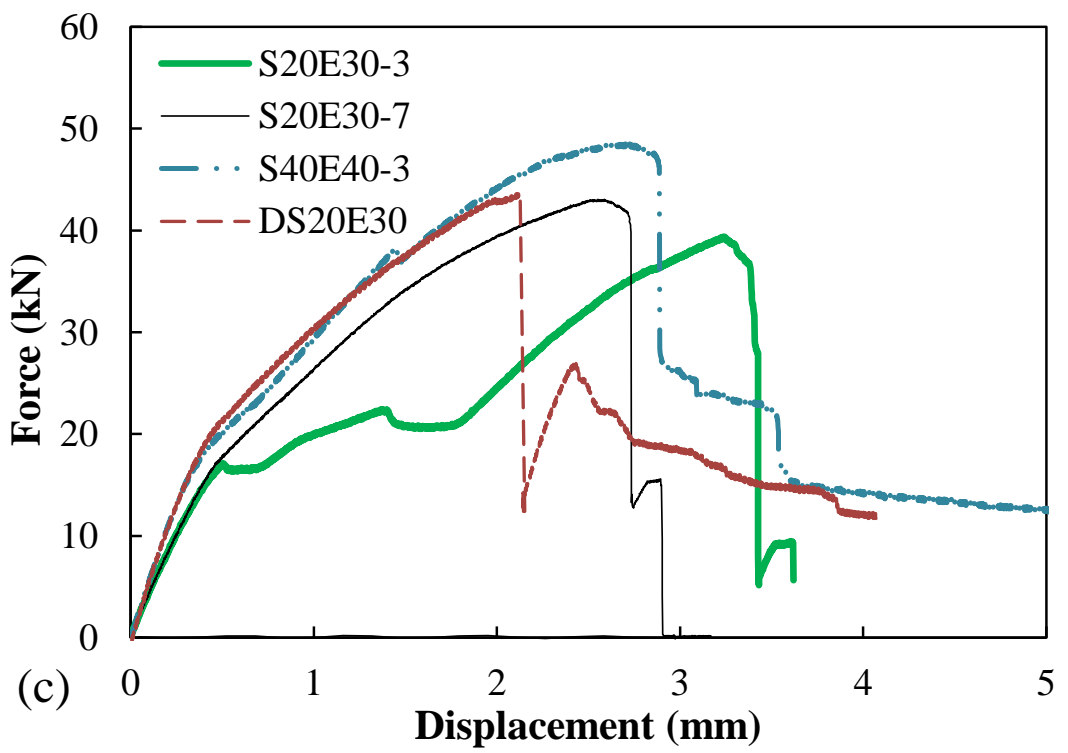

Figure 4. Typical failure damages of GFRP (a) Inner face S20E30, (b) Outer face S40E40, (c) Typical force-displacement curves of S20E30 compared to S40E40 and DS20F.30 
(a)

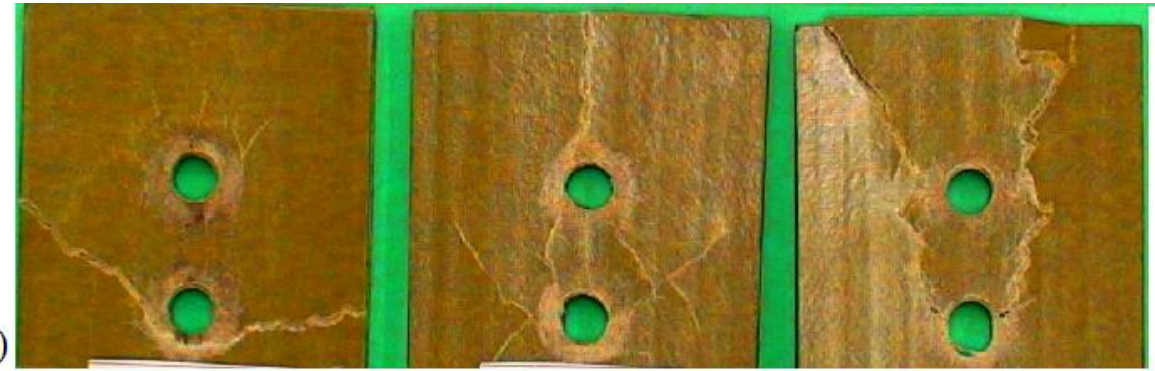

(b)

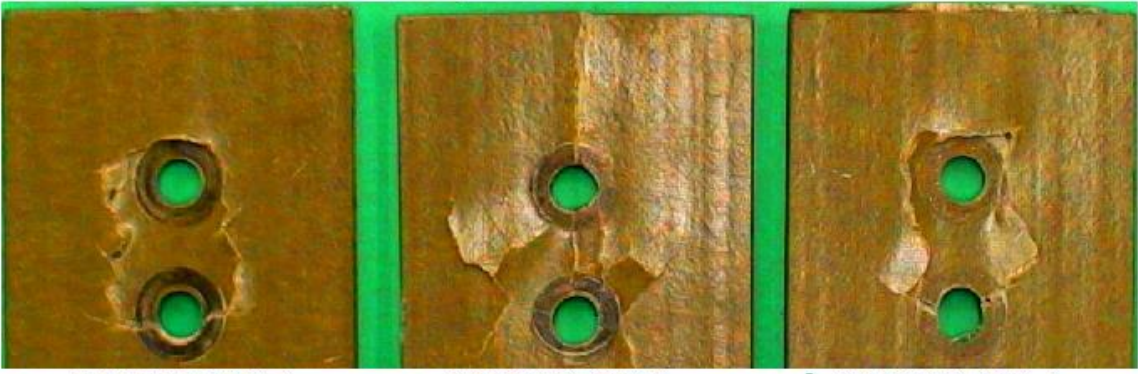

S40E40P30-1

S40E40P30-2

S40E40P30-4

(c)

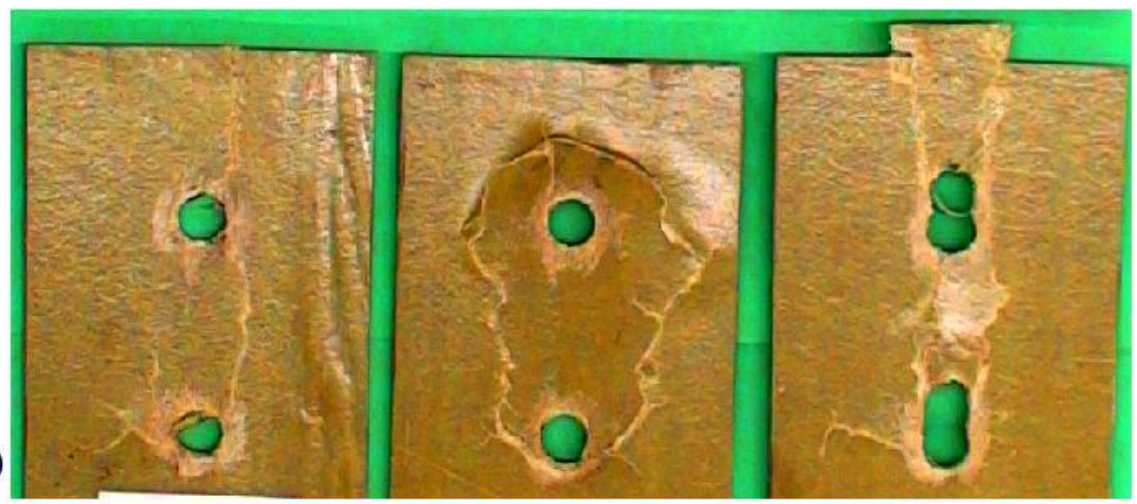

(d)

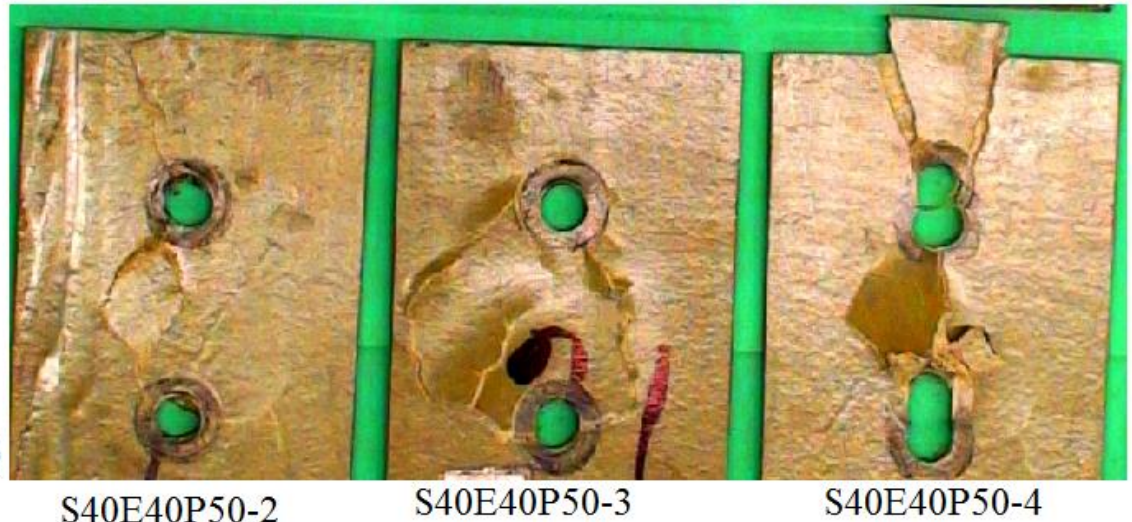

Figure 5. Failure damages of GFRP (a) Inner face of S40E40P30 (b) Outer face of 768 S40E40P30, (c) Inner face of S40E40P50 (d) Outer face of S40E40P50. 

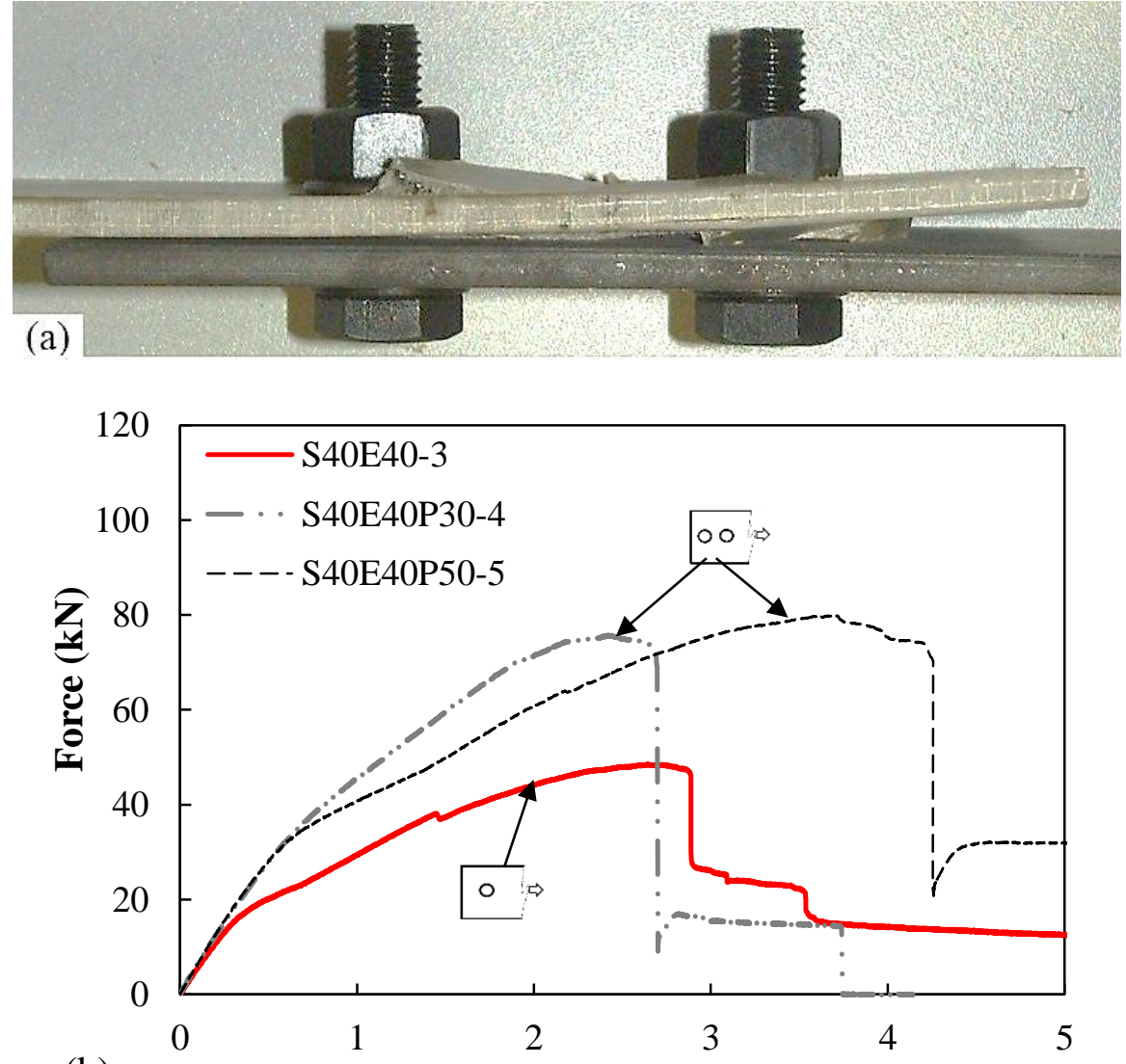

(b)

Displacement (mm)

Figure 6. (a) Out-of-plane deformation of a two bolt-column, (b) Typical force-displacement curves of S40E40P30 compared to S40E40P50, S40E40 


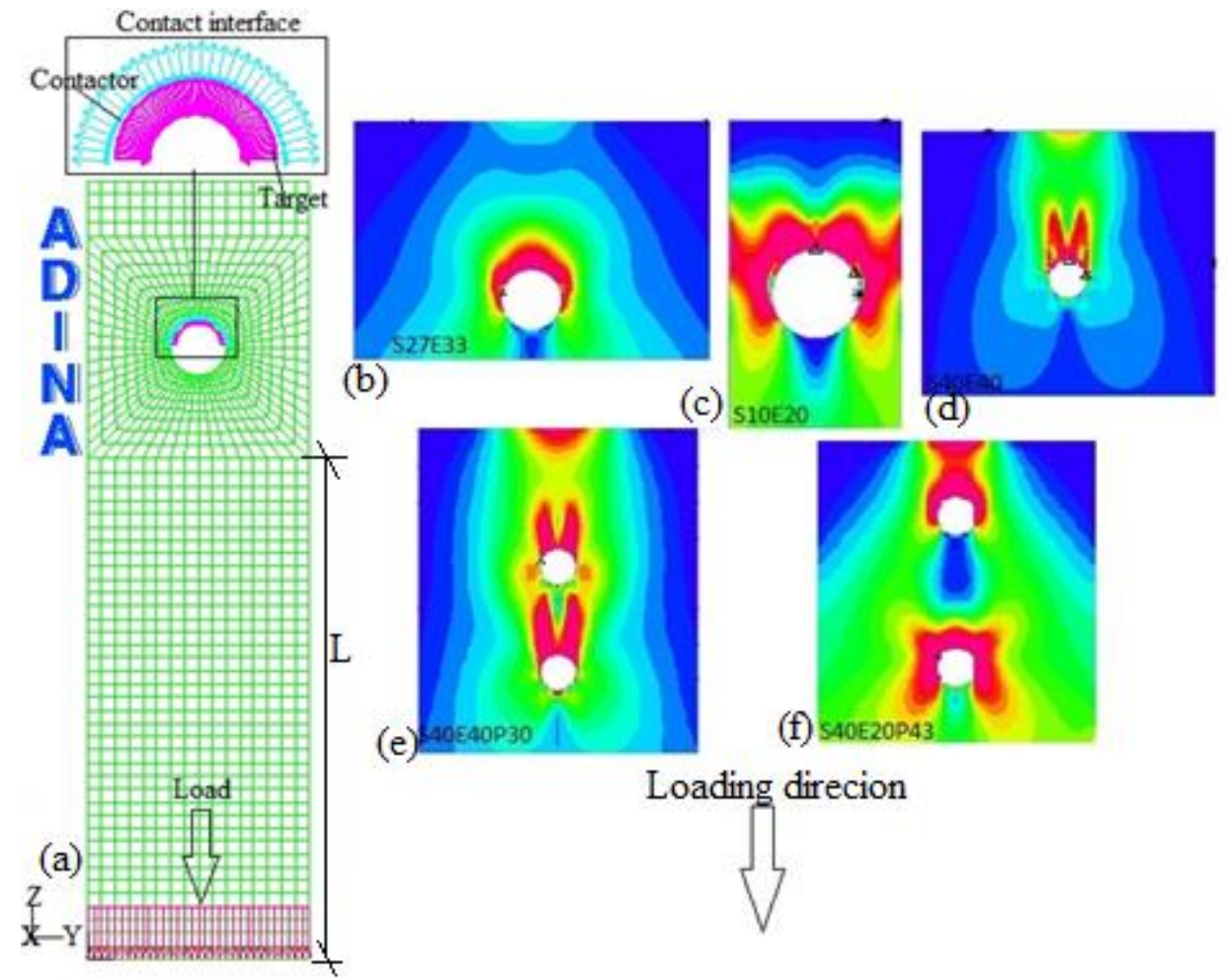

Figure 7. (a) Typical 2D model, Post-processing failure modes: (b) bearing, 772 (c) net-section, (d) and (e) shear tear-out, (f) cleavage 

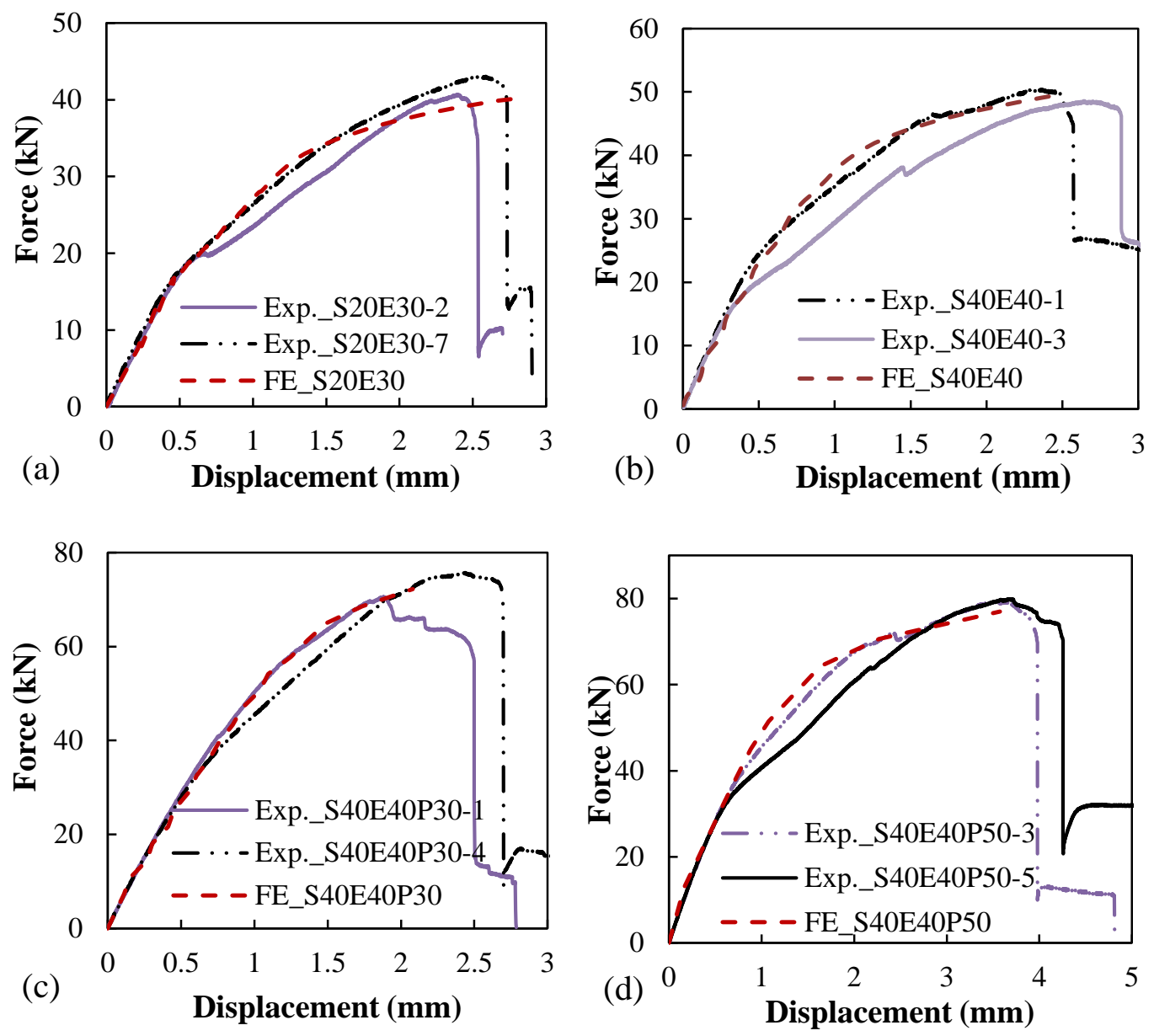

Figure 8. Typical force-displacement curves of the experimental compared to finite element models: (a) S20E30, (b) S40E40, (c) S40E40P3, (d) S40E40P50 

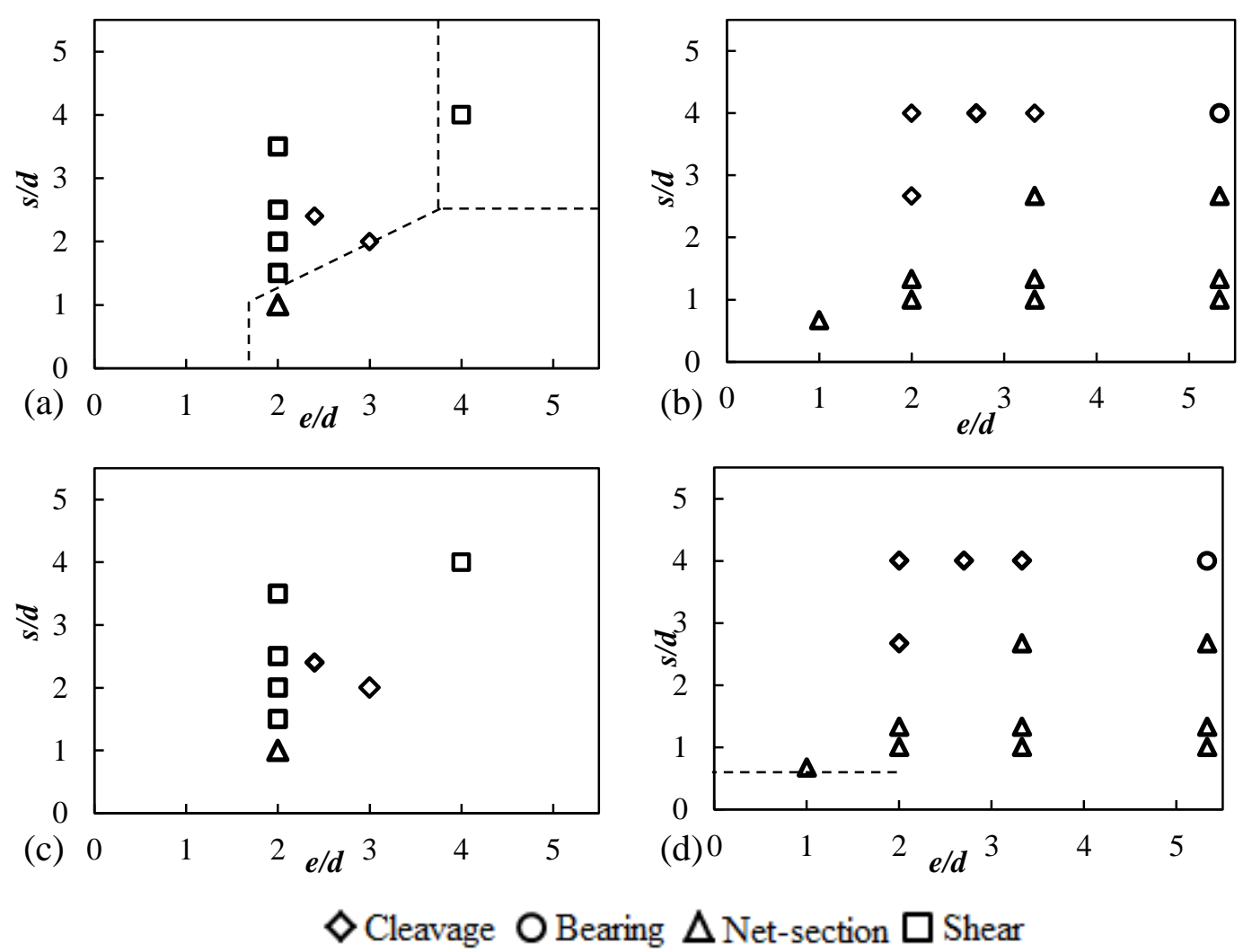

Figure 9. Effect of $e / d$ and $s / d$ on failure modes for one-bolt: (a) FE and Exp. failure modes for highly orthotropic plates; (b) FE and Exp. failure modes for quasi-isotropic plates; (c) [1] and Exp. failure modes for highly orthotropic plates; (d) [1] and Exp. failure modes for quasi-isotropic plates; 

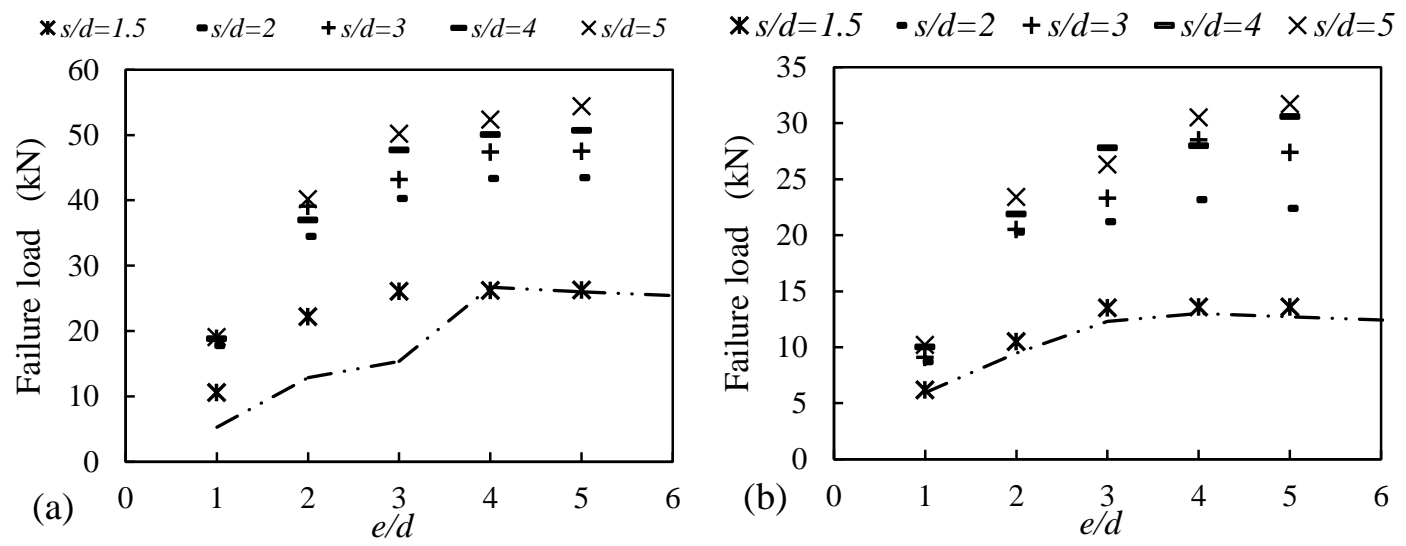

Figure 10. Effect of $e / d$ and $s / d$ on joint strength for one-bolt: (a) FE failure loads for highly orthotropic plates; (b) FE failure loads for quasi-isotropic plates 

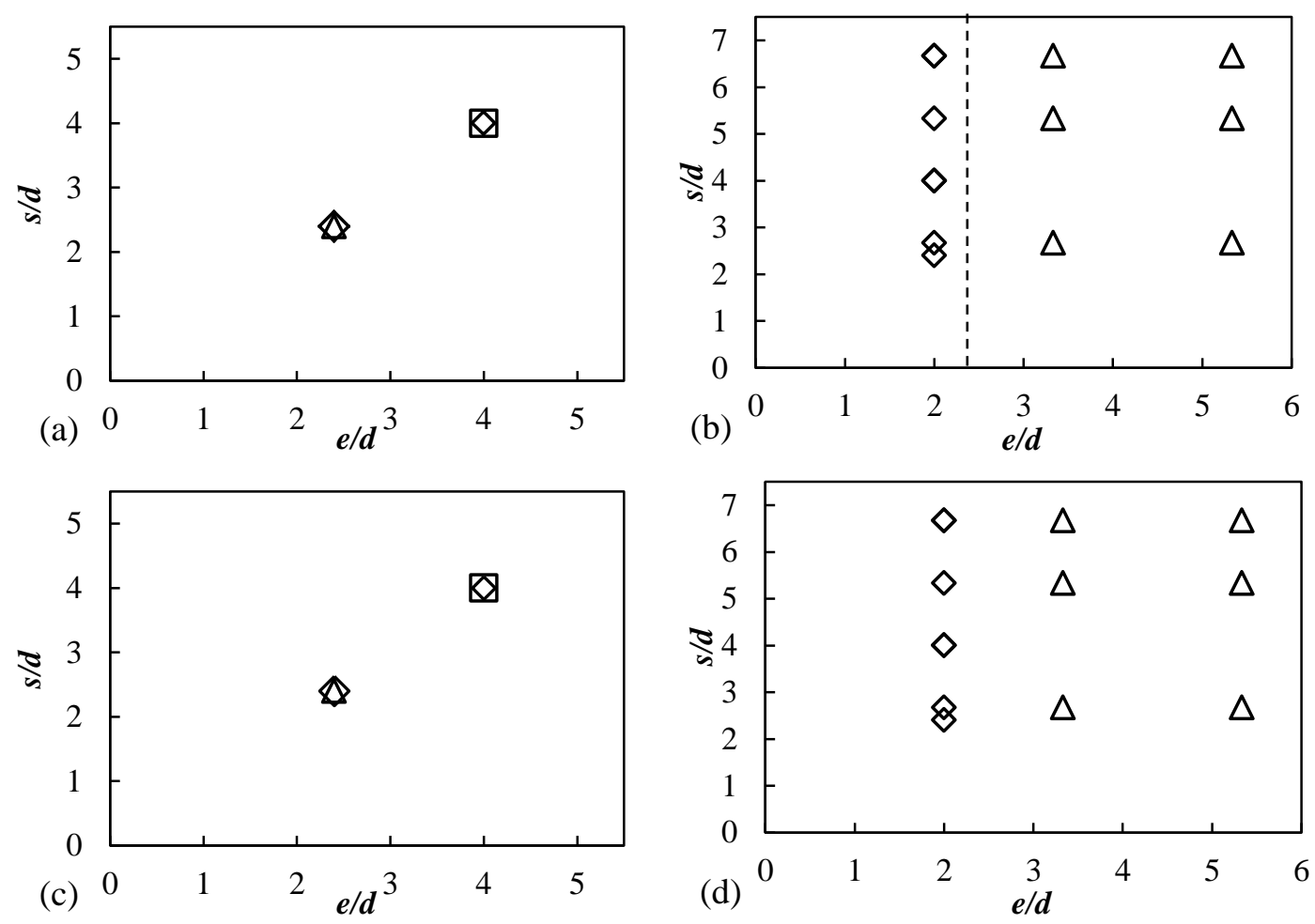

\section{$\diamond$ Cleavage $\Delta$ Net-section $\square$ Shear}

Figure 11. Effect of geometric parameters on failure modes for two-bolt: (a) FE and Exp. failure modes for highly orthotropic plates; (b) FE and Exp. failure modes for quasi-isotropic plates; (c) [1] and Exp. failure modes for highly orthotropic plates; (d)

[1] and Exp. failure modes for quasi-isotropic plates 

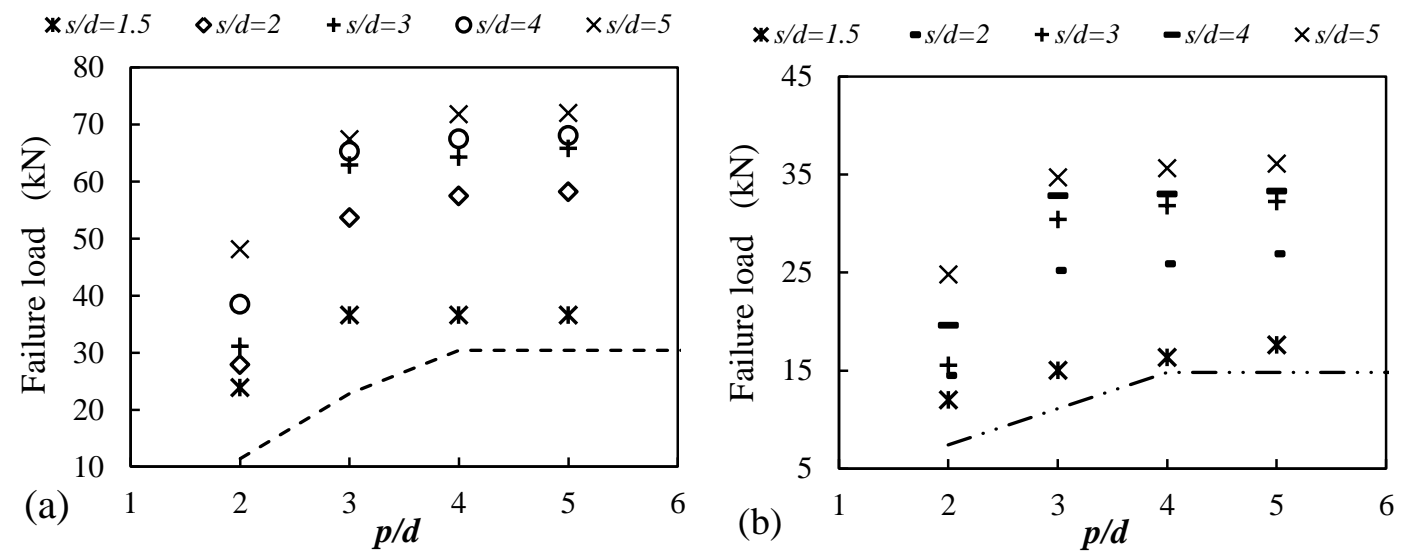

Figure 12. Effect of geometric parameters on joint strength for two-bolt: (a) FE failure loads for highly orthotropic plates; (b) FE failure loads for quasi-isotropic plates 
Table 1. Minimum geometric requirements from design manuals ( $d$ : diameter of the bolt, $d_{h}$ : bolt-hole)

\begin{tabular}{lcccc}
\hline & $\begin{array}{c}\text { Pitch } \\
(\boldsymbol{p})\end{array}$ & $\begin{array}{c}\text { Gage } \\
(\boldsymbol{g})\end{array}$ & $\begin{array}{c}\text { End-distance } \\
(\boldsymbol{e})\end{array}$ & $\begin{array}{c}\text { Side- } \\
\text { distance }(\boldsymbol{s})\end{array}$ \\
\hline ASCE [1] & $4 d$ & $4 d$ & $\begin{array}{c}4 d \text { for lbolt } \\
2 d \text { for } \text { multi-row }\end{array}$ & $1.5 d$ \\
\hline EUROCOMP [2] & $4 d_{h}$ & $4 d_{h}$ & $3 d_{h ;}$ and $s / d_{h}$ & $0.5 g$ \\
\hline CNR -DT [3] & $4 d$ & $4 d$ & $4 d$ & $0.5 g$ \\
\hline Strongwell [4] & $5 d$ & $5 d$ & $3 d$ & $2 d$ \\
\hline $\begin{array}{l}\text { Creative Pultrusion } \\
\text { [5] }\end{array}$ & $3 d$ & $3 d$ & $3 d$ & $2 d$ \\
\hline $\begin{array}{l}\text { Fibreline } \\
\text { Composite [6] }\end{array}$ & $4 d$ & $4 d$ & $3.5 d$ & $2 d$ \\
\hline
\end{tabular}

786 
Table 2. Mechanical properties of the materials

\begin{tabular}{lccc}
\hline Reference & Tested & {$[10]$} & {$[17]$} \\
\hline Ratio of $E_{T t} / E_{L t}$ & 0.2 & 0.7 & 0.8 \\
\hline Longitudinal modulus $E_{L t}(\mathrm{GPa})$ & 18.6 & 15.2 & 12.8 \\
Transversal modulus $E_{T t}(\mathrm{GPa})$ & 4.03 & 10.8 & 10.7 \\
In plane shear modulus $G(\mathrm{GPa})$ & 4.80 & 4.2 & 4.2 \\
Longitudinal tensile strength $f_{u L t}(\mathrm{MPa})$ & 340 & 198 & 166 \\
Transversal tensile strength $f_{u T_{t}}(\mathrm{MPa})$ & 88.4 & 101 & 110 \\
In plane shear strength $f_{i p s h}(\mathrm{MPa})$ & 104.2 & 121 & 117 \\
Longitudinal Poisson ratio $v_{\mathrm{Lt}}$ & $0.33^{*}$ & 0.28 & 0.28 \\
\hline
\end{tabular}

( )* Reported by manufacturer 
Table 3. Tests results of bolted joints

\begin{tabular}{cccc}
\hline Tests names & Failure mode & $\begin{array}{c}\text { Load } \\
\text { (kN) }\end{array}$ & $\begin{array}{c}\text { Displacement } \\
\text { at peak load }\end{array}$ \\
\hline S20E30-1 & Cleavage & 40.09 & 3.71 \\
S20E30-2 & Cleavage & 44.11 & 2.97 \\
S20E30-3 & Net-section & 39.35 & 3.24 \\
S20E30-4 & Cleavage & 40.86 & 2.46 \\
S20E30-5 & Net-section & 40.68 & 2.39 \\
S20E30-6 & Shear & 40.64 & 2.60 \\
S20E30-7 & Cleavage & 43.03 & 2.59 \\
\hline DS20E30-1 & Cleavage & 43.58 & 2.11 \\
DS20E30-2 & Cleavage & 42.24 & 1.99 \\
DS20E30-3 & Cleavage & 44.39 & 1.87 \\
\hline S40E40-1 & Shear & 50.48 & 2.33 \\
S40E40-2 & Shear & 48.96 & 2.01 \\
S40E40-3 & Shear & 48.56 & 2.65 \\
S40E40-4 & Cleavage & 41.32 & 2.37 \\
S40E40-5 & Shear & 50.05 & 2.28 \\
\hline & Net-section on inner & \\
S40E40P30-1 & face, shear on outer & 71.00 & 1.88 \\
& face & 77.09 & 2.11 \\
S40E40P30-2 & Cleavage & 77.11 & 2.06 \\
S40E40P30-3 & Shear & 75.53 & 2.42 \\
S40E40P30-4 & Shear & 76.65 & 2.06 \\
S40E40P30-5 & Cleavage & 80.83 & 3.38 \\
\hline S40E40P50-1 & Shear & 4.28 \\
S40E40P50-2 & Cleavage & 72.61 & 3.65 \\
S40E40P50-3 & Shear & 80.61 & 4.28 \\
S40E40P50-4 & Shear & 76.58 & 3.50 \\
S40E40P50-5 & Shear & 79.63 & \\
\hline & & & \\
& &
\end{tabular}


Table 4. Comparison of experimental to predicted results

\begin{tabular}{|c|c|c|c|c|c|c|c|c|c|c|}
\hline & \multirow{2}{*}{$\begin{array}{l}\text { Ave. } \\
\mathrm{P}_{\text {exp }} \\
(\mathrm{kN})\end{array}$} & \multirow[t]{2}{*}{$\begin{array}{l}\text { Exp. } \\
\text { FM }\end{array}$} & \multicolumn{5}{|c|}{$\begin{array}{c}\text { Strength (kN) calculated using } \\
\text { equations } 1 \text { to } 7\end{array}$} & \multicolumn{2}{|c|}{$\begin{array}{l}\text { Governed } \\
\text { prediction }\end{array}$} & \multirow{2}{*}{$\begin{array}{r}P_{\text {pred }} / P_{\text {exp }} \\
(2) /(8)\end{array}$} \\
\hline & & & $\mathrm{R}_{\mathrm{nt}}$ & $\mathrm{R}_{\mathrm{sh}}$ & $\mathrm{R}_{\mathrm{cl}}$ & $\mathrm{R}_{\mathrm{cl}}$ & $\mathrm{R}_{\mathrm{br}}$ & FL & FM & \\
\hline (1) & (2) & (3) & (4) & (5) & (6) & (7) & $(8)$ & (9) & (10) & (11) \\
\hline Equation & - & - & 1 or 2 & 3 or 4 & 6 & 7 & 5 & - & - & - \\
\hline S20E30 & 41.3 & $\mathrm{~S} / \mathrm{C}$ & 35.5 & 28.8 & 19.5 & 44.3 & 49.4 & 19.5 & $\mathbf{C}$ & 0.47 \\
\hline DS20E30 & 43.4 & C & 35.5 & 28.8 & 19.5 & 44.3 & 49.4 & 19.5 & $\mathbf{C}$ & 0.45 \\
\hline S40E40 & 47.9 & $\mathrm{~S} / \mathrm{C}$ & 50.7 & 40.5 & $38.4^{*}$ & $48.2 *$ & 49.4 & 40.5 & $\mathbf{S}$ & 0.85 \\
\hline S40E40P30 & 75.5 & $\mathrm{~S} / \mathrm{C}$ & 48.2 & 75.7 & - & - & 74.0 & 48.2 & $\mathbf{N}$ & 0.64 \\
\hline S40E40P50 & 78.1 & $\mathbf{S}$ & 64.3 & 99.2 & - & - & 98.7 & 64.3 & $\mathbf{N}$ & 0.82 \\
\hline
\end{tabular}

801

802

803

804

805

806

807

808

809

810

811

812

813

814

815

816

817

818

819

820

821

822

823

824

825

826

827

828

829
* Value calculated but not recommended by [1] for $e / d \geq 4$; FL: failure load; FM: failure mode; $\mathrm{N}$ : net-section failure; $\mathrm{S}$ : shear tear-out failure; $\mathrm{C}$ : cleavage failure 
Table 5 Model validation

\begin{tabular}{|c|c|c|c|c|c|c|}
\hline & Configuration & $\begin{array}{c}\mathrm{P}_{\exp } \\
(\mathrm{kN})\end{array}$ & $\begin{array}{c}\text { Exp. } \\
\text { FM }\end{array}$ & $\begin{array}{c}\mathrm{P}_{\mathrm{FE}} \\
(\mathrm{kN})\end{array}$ & $\begin{array}{c}\text { FE } \\
\text { FM }\end{array}$ & $\mathrm{P}_{\mathrm{FE}} / \mathrm{P}_{\mathrm{Exp}}$ \\
\hline \multirow{3}{*}{ Tested/ (1X1) } & S30E20 & 41.3 & $\mathrm{C} / \mathrm{S}$ & 40.2 & $\mathrm{C}$ & 0.97 \\
\hline & DS20E30 & 43.4 & $\mathrm{C}$ & 40.2 & $\mathrm{C}$ & 0.92 \\
\hline & S40E40 & 47.8 & $S$ & 49.7 & $\mathrm{~S}$ & 1.04 \\
\hline \multirow{2}{*}{ Tested/ (1X2) } & S40E40P30 & 75.5 & $\mathrm{C} / \mathrm{S}$ & 72.2 & $\mathrm{~S}$ & 0.96 \\
\hline & S40E40P50 & 78.1 & S & 77.0 & $\mathrm{~S}$ & 0.99 \\
\hline$[10] /(1 X 1)$ & S07E10 & 6.1 & $\mathrm{~N}$ & 6.65 & $\mathrm{~N}$ & 1.09 \\
\hline$d=19.05 \mathrm{~mm}$, & S10E20 & 22 & $\mathrm{~N}$ & 21.2 & $\mathrm{~N}$ & 0.96 \\
\hline$t=9.53 \mathrm{~mm}$ & S27E33 & 47.7 & $\mathrm{~B}+\mathrm{N}$ & 46.3 & B & 0.97 \\
\hline$[17] /(1 X 2)$ & S27E33P43 & 84.2 & $\mathrm{~N}$ & 82.3 & $\mathrm{~N}$ & 0.98 \\
\hline$d=19.05 \mathrm{~mm}$, & S40E20P43 & 96.8 & $\mathrm{C}$ & 96.15 & $\mathrm{C}$ & 0.99 \\
\hline$t=12.7 \mathrm{~mm}$ & S40E33P43 & 102.4 & $\mathrm{~N}$ & 98.9 & $\mathrm{~N}$ & 0.96 \\
\hline$[17] /(2 X 1)$ & S33E20G43 & 96.8 & $\mathrm{C}$ & 91.9 & $\mathrm{C}$ & 0.95 \\
\hline$d=19.05 \mathrm{~mm}$, & S33E33G43 & 105.8 & $\mathrm{~N}$ & 101.8 & $\mathrm{~N}$ & 0.96 \\
\hline$t=12.7 \mathrm{~mm}$ & S47E20G43 & 97.2 & $\mathrm{C}$ & 92.1 & $\mathrm{C}$ & 0.95 \\
\hline
\end{tabular}


Table 6. FE results: failure load $(\mathrm{kN}) /$ failure mode

\begin{tabular}{|c|c|c|c|c|c|c|c|c|c|c|c|c|c|}
\hline \multirow[b]{2}{*}{$s / d$} & \multicolumn{6}{|c|}{$e / d$} & \multicolumn{7}{|c|}{$e / d$} \\
\hline & $p / d$ & 1 & 2 & 3 & 4 & 5 & $s / d$ & $p / d$ & 1 & 2 & 3 & 4 & 5 \\
\hline & \multicolumn{6}{|c|}{ One-bolt (For $\left.\mathrm{E}_{\mathrm{T} t} / \mathrm{E}_{\mathrm{Lt}}=0.2\right)$} & \multicolumn{7}{|c|}{ One-bolt (For $\left.\mathrm{E}_{\mathrm{T} t} / \mathrm{E}_{\mathrm{Lt}}=0.8\right)$} \\
\hline 1 & - & $6.2 / \mathrm{C}$ & $11.7 / \mathrm{N}$ & $12.5 / \mathrm{N}$ & $12.5 / \mathrm{N}$ & $12.7 / \mathrm{N}$ & 1 & - & $4.2 / \mathrm{N}$ & $6.3 / \mathrm{N}$ & $6.3 / \mathrm{N}$ & $6.3 / \mathrm{N}$ & $6.3 / \mathrm{N}$ \\
\hline 1.5 & - & $10.6 / \mathrm{C}$ & $22.2 / \mathrm{C}$ & $26.1 / \mathrm{N}$ & $26.2 / \mathrm{N}$ & $26.3 / \mathrm{N}$ & 1.5 & - & $6.2 / \mathrm{C}$ & $10.5 / \mathrm{C}$ & $13.5 / \mathrm{N}$ & $13.6 / \mathrm{N}$ & $13.6 / \mathrm{N}$ \\
\hline 2 & - & $17.8 / \mathrm{C}$ & $34.5 / \mathrm{C}$ & $40.2 / \mathrm{C}$ & $43.4 / \mathrm{N}$ & $43.5 / \mathrm{N}$ & 2 & - & $8.7 / \mathrm{C}$ & $20.3 / \mathrm{C}$ & $21.2 / \mathrm{N}$ & $23.2 / \mathrm{N}$ & $22.4 / \mathrm{N}$ \\
\hline 3 & - & $18.9 / \mathrm{C}$ & $35.1 / \mathrm{C}$ & $43.2 / \mathrm{C}$ & $47.4 / \mathrm{S}$ & $47.5 / \mathrm{S}$ & 3 & - & $9.1 / \mathrm{C}$ & $20.5 / \mathrm{C}$ & 23.3/B & 28.5/B & 27.4/B \\
\hline 4 & - & $18.8 / \mathrm{C}$ & $37.0 / \mathrm{C}$ & $47.7 / \mathrm{C}$ & $49.7 / \mathrm{S}$ & $50.7 / \mathrm{S}$ & 4 & - & $10.0 / \mathrm{C}$ & $21.9 / \mathrm{C}$ & 27.8/B & 28.0/B & $30.6 / \mathrm{B}$ \\
\hline \multirow[t]{2}{*}{5} & - & $19.1 / \mathrm{C}$ & $40.2 / \mathrm{C}$ & $50.2 / \mathrm{C}$ & $52.4 / \mathrm{S}$ & $54.4 / \mathrm{S}$ & 5 & - & $10.2 / \mathrm{C}$ & $23.4 / \mathrm{C}$ & 26.3/B & $30.5 / \mathrm{B}$ & $31.7 / \mathrm{B}$ \\
\hline & \multicolumn{6}{|c|}{ Two-bolt $\left(\right.$ For $\left.\mathrm{E}_{\mathrm{T}} / \mathrm{E}_{\mathrm{Lt}}=0.2\right)$} & \multicolumn{7}{|c|}{ Two-bolt (For $\left.\mathrm{E}_{\mathrm{T} t} / \mathrm{E}_{\mathrm{Lt}}=0.8\right)$} \\
\hline \multirow{4}{*}{1.5} & 2 & $20.3 / \mathrm{C}$ & $23.9 / \mathrm{S}$ & $25.6 / \mathrm{S}$ & $27.9 / \mathrm{N}$ & $28.8 / \mathrm{N}$ & \multirow{4}{*}{1.5} & 2 & $10.1 / \mathrm{C}$ & $12.0 / \mathrm{N}$ & $12.9 / \mathrm{N}$ & 13.1./N & $13.4 / \mathrm{N}$ \\
\hline & 3 & $28.2 / \mathrm{C}$ & $36.6 / \mathrm{N}$ & $37.9 / \mathrm{N}$ & $38.2 / \mathrm{N}$ & $38.8 / \mathrm{N}$ & & 3 & $14.7 / \mathrm{C}$ & $15.0 / \mathrm{N}$ & $15.1 / \mathrm{N}$ & $15.2 / \mathrm{N}$ & $15.2 / \mathrm{N}$ \\
\hline & 4 & $31.1 / \mathrm{C}$ & $36.6 / \mathrm{N}$ & $38.0 / \mathrm{N}$ & $38.5 / \mathrm{N}$ & $38.8 / \mathrm{N}$ & & 4 & $14.9 / \mathrm{C}$ & $16.3 / \mathrm{N}$ & $17.2 / \mathrm{N}$ & $17.4 / \mathrm{N}$ & $17.4 / \mathrm{N}$ \\
\hline & 5 & $32.6 / \mathrm{C}$ & $36.6 / \mathrm{N}$ & $38.1 / \mathrm{N}$ & $38.5 / \mathrm{N}$ & $38.9 / \mathrm{N}$ & & 5 & $14.9 / \mathrm{C}$ & $17.6 / \mathrm{N}$ & $17.8 / \mathrm{N}$ & $17.6 / \mathrm{N}$ & $18.1 / \mathrm{N}$ \\
\hline \multirow{4}{*}{2} & 2 & $25.4 / \mathrm{C}$ & $27.9 / \mathrm{S}$ & $31.0 / \mathrm{S}$ & $33.9 / \mathrm{S}$ & $33.6 / \mathrm{S}$ & \multirow{4}{*}{2} & 2 & $12.1 / \mathrm{C}$ & $14.5 / \mathrm{C}$ & $15.5 / \mathrm{N}$ & $15.9 / \mathrm{N}$ & $16.3 / \mathrm{N}$ \\
\hline & 3 & $39.5 / \mathrm{C}$ & $53.7 / \mathrm{S}$ & $55.8 / \mathrm{S}$ & $55.8 / \mathrm{S}$ & $55.8 / \mathrm{S}$ & & 3 & $21.2 / \mathrm{C}$ & $25.2 / \mathrm{C}$ & $25.7 / \mathrm{N}$ & $25.7 / \mathrm{N}$ & $25.8 / \mathrm{N}$ \\
\hline & 4 & $40.1 / \mathrm{C}$ & $57.5 / \mathrm{S}$ & $58.7 / \mathrm{S}$ & $65.1 / \mathrm{S}$ & $66.3 / \mathrm{S}$ & & 4 & $22.1 / \mathrm{C}$ & $25.9 / \mathrm{C}$ & $26.5 / \mathrm{N}$ & $28.0 / \mathrm{N}$ & $28.1 / \mathrm{N}$ \\
\hline & 5 & $40.7 / \mathrm{C}$ & $58.2 / \mathrm{S}$ & $59.5 / \mathrm{S}$ & $66.9 / \mathrm{S}$ & $67.2 / \mathrm{S}$ & & 5 & $22.4 / \mathrm{C}$ & $26.9 / \mathrm{C}$ & $27.2 / \mathrm{N}$ & $29.4 / \mathrm{N}$ & $29.5 / \mathrm{N}$ \\
\hline \multirow{4}{*}{3} & 2 & $28.5 / \mathrm{C}$ & $31.1 / \mathrm{S}$ & $33.6 / \mathrm{S}$ & $34.3 / \mathrm{S}$ & $34.4 / \mathrm{S}$ & \multirow{4}{*}{3} & 2 & $14.3 / \mathrm{C}$ & $15.5 / \mathrm{C}$ & $16.8 / \mathrm{N}$ & $17.6 / \mathrm{N}$ & $17.6 / \mathrm{N}$ \\
\hline & 3 & $54.5 / \mathrm{C}$ & $62.9 / \mathrm{S}$ & $65.0 / \mathrm{S}$ & $69.9 / \mathrm{S}$ & $70.4 / \mathrm{S}$ & & 3 & $25.4 / \mathrm{C}$ & $30.4 / \mathrm{C}$ & $31.3 / \mathrm{N}$ & $32.3 / \mathrm{N}$ & $32.5 / \mathrm{N}$ \\
\hline & 4 & $54.8 / \mathrm{C}$ & $64.3 / \mathrm{S}$ & $67.2 / \mathrm{S}$ & $70.3 / \mathrm{S}$ & $70.8 / \mathrm{S}$ & & 4 & $26.2 / \mathrm{C}$ & $31.8 / \mathrm{C}$ & $32.1 / \mathrm{N}$ & $32.8 / \mathrm{N}$ & $33.7 / \mathrm{N}$ \\
\hline & 5 & $55.1 / \mathrm{S}$ & $65.8 / \mathrm{S}$ & $70.3 / \mathrm{S}$ & $75.7 / \mathrm{S}$ & $76.0 / \mathrm{S}$ & & 5 & $27.2 / \mathrm{C}$ & $32.2 / \mathrm{C}$ & $33.4 / \mathrm{N}$ & $35.2 / \mathrm{N}$ & $35.4 / \mathrm{N}$ \\
\hline \multirow{4}{*}{4} & 2 & $36.1 / \mathrm{C}$ & $38.5 / \mathrm{S}$ & $41.8 / \mathrm{S}$ & $43.3 / \mathrm{S}$ & $44.8 / \mathrm{S}$ & \multirow{4}{*}{4} & 2 & $18.9 / \mathrm{C}$ & $19.6 / \mathrm{C}$ & $19.7 / \mathrm{N}$ & $20.9 / \mathrm{N}$ & $21.6 / \mathrm{N}$ \\
\hline & 3 & $60.2 / \mathrm{C}$ & $65.3 / \mathrm{S}$ & $69.5 / \mathrm{S}$ & $72.2 / \mathrm{S}$ & $73.5 / \mathrm{S}$ & & 3 & $30.1 / \mathrm{C}$ & $32.8 / \mathrm{C}$ & $36.4 / \mathrm{N}$ & $37.5 / \mathrm{N}$ & $37.8 / \mathrm{N}$ \\
\hline & 4 & $63.7 / \mathrm{C}$ & $67.5 / \mathrm{S}$ & $71.4 / \mathrm{S}$ & $74.9 / \mathrm{S}$ & $76.1 / \mathrm{S}$ & & 4 & $30.7 / \mathrm{C}$ & $33.0 / \mathrm{C}$ & $37.3 / \mathrm{N}$ & $38.0 / \mathrm{N}$ & $38.1 / \mathrm{N}$ \\
\hline & 5 & $63.8 / \mathrm{C}$ & $68.1 / \mathrm{S}$ & $73.5 / \mathrm{S}$ & $77.0 / \mathrm{S}$ & $78.6 / \mathrm{S}$ & & 5 & $30.7 / \mathrm{C}$ & $33.3 / \mathrm{C}$ & $38.3 / \mathrm{N}$ & $38.4 / \mathrm{N}$ & $38.4 / \mathrm{N}$ \\
\hline \multirow{4}{*}{5} & 2 & $44.7 / \mathrm{C}$ & $48.1 / \mathrm{S}$ & $51.1 / \mathrm{S}$ & $53.3 / \mathrm{S}$ & $54.6 / \mathrm{S}$ & \multirow{4}{*}{5} & 2 & $22.3 / \mathrm{C}$ & $24.8 / \mathrm{C}$ & $25.8 / \mathrm{N}$ & $26.3 / \mathrm{N}$ & $26.9 / \mathrm{N}$ \\
\hline & 3 & $63.4 / \mathrm{C}$ & $67.4 / \mathrm{S}$ & $69.8 / \mathrm{S}$ & $75.6 / \mathrm{S}$ & $75.6 / \mathrm{S}$ & & 3 & $31.1 / \mathrm{C}$ & $34.7 / \mathrm{C}$ & $39.2 / \mathrm{N}$ & $40.8 / \mathrm{N}$ & $41.8 / \mathrm{N}$ \\
\hline & 4 & $63.5 / \mathrm{C}$ & $71.8 / \mathrm{S}$ & $75.3 / \mathrm{S}$ & $78.1 / \mathrm{S}$ & $79.0 / \mathrm{S}$ & & 4 & $31.6 / \mathrm{C}$ & $35.6 / \mathrm{C}$ & $39.2 / \mathrm{N}$ & $41.1 / \mathrm{N}$ & $42.0 / \mathrm{N}$ \\
\hline & 5 & $64.2 / \mathrm{C}$ & $72.0 / \mathrm{S}$ & $78.8 / \mathrm{S}$ & $79.9 / \mathrm{S}$ & $80.3 / \mathrm{S}$ & & 5 & $32.0 / \mathrm{C}$ & $36.1 / \mathrm{C}$ & $39.4 / \mathrm{N}$ & $41.5 / \mathrm{N}$ & $42.0 / \mathrm{N}$ \\
\hline
\end{tabular}


Table 7. Experimental failure modes

\begin{tabular}{|c|c|c|c|c|c|c|c|c|c|}
\hline \multicolumn{6}{|c|}{ One bolt (1X1) } & \multicolumn{4}{|c|}{ Two-bolt (1X2) } \\
\hline e/d & $s / d$ & FM & e/d & $s / d$ & FM & $p / d$ & e/d & $s / d$ & FM \\
\hline \multicolumn{3}{|c|}{$\mathrm{E}_{\mathrm{T}} / \mathrm{E}_{\mathrm{Lt}}=0.2$ Tested } & \multicolumn{3}{|c|}{$\mathrm{E}_{\mathrm{Tt}} / \mathrm{E}_{\mathrm{tt}}=0.7[13]$} & \multicolumn{4}{|c|}{$\mathrm{E}_{\mathrm{T} \mathrm{t}} / \mathrm{E}_{\mathrm{t} \mathrm{t}}=0.2$ Tested } \\
\hline 3 & 2 & $\mathrm{C}$ & 1 & 0.7 & $\mathrm{~N}$ & 3 & 4 & 4 & $\mathrm{~S} / \mathrm{C}$ \\
\hline 4 & 4 & $S$ & 10.7 & 0.7 & $\mathrm{~N}$ & 5 & 4 & 4 & $S$ \\
\hline \multicolumn{3}{|c|}{$\mathrm{E}_{\mathrm{T} t} / \mathrm{E}_{\mathrm{Lt}}=0.3[17]$} & 2 & 1 & $\mathrm{~N}$ & \multicolumn{4}{|c|}{$\mathrm{E}_{\mathrm{T} t} / \mathrm{E}_{\mathrm{Lt}}=0.3[36]$} \\
\hline 2 & 1 & $\mathrm{~N}$ & 3.3 & 1 & $\mathrm{~N}$ & 4 & 2.4 & 2.4 & $\mathrm{~N} / \mathrm{C}$ \\
\hline 2 & 1.5 & $\mathrm{~S}$ & 5.3 & 1 & $\mathrm{~N}$ & \multicolumn{4}{|c|}{$\mathrm{E}_{\mathrm{Tt}} / \mathrm{E}_{\mathrm{Lt}}=0.8[37]$} \\
\hline 2 & 2 & S & 2 & 1.3 & $\mathrm{~N}$ & 4.3 & 2 & 2.7 & $\mathrm{C}$ \\
\hline 2 & 2.5 & $\mathrm{~S}$ & 3.3 & 1.3 & $\mathrm{~N}$ & 4.3 & 3.3 & 2.7 & $\mathrm{~N}$ \\
\hline 2 & 3.5 & $\mathrm{~S}$ & 5.3 & 1.3 & $\mathrm{~N}$ & 4.3 & 5.3 & 2.7 & $\mathrm{~N}$ \\
\hline \multicolumn{3}{|c|}{$\mathrm{E}_{\mathrm{T}} \mathrm{E}_{\mathrm{LL}}=0.3[36]$} & 2 & 2.7 & $\mathrm{C}$ & 4.3 & 2 & 4 & $\mathrm{C}$ \\
\hline \multirow[t]{13}{*}{2.4} & 2.4 & $\mathrm{C}$ & 3.3 & 2.7 & $\mathrm{~N}$ & 4.3 & 3.3 & 4 & $\mathrm{~N}$ \\
\hline & & & 5.3 & 2.7 & $\mathrm{~N}$ & 4.3 & 5.3 & 4 & $\mathrm{~N}$ \\
\hline & & & 10.7 & 2.7 & $\mathrm{~N}$ & 4.3 & 2 & 5.3 & $\mathrm{C}$ \\
\hline & & & 2 & 4 & $\mathrm{C}$ & 4.3 & 3.3 & 5.3 & $\mathrm{~N}$ \\
\hline & & & 3.3 & 4 & $\mathrm{C}$ & 4.3 & 5.3 & 5.3 & $\mathrm{~N}$ \\
\hline & & & 5.3 & 4 & B & 4.3 & 2 & 6.7 & $\mathrm{C}$ \\
\hline & & & 1 & 6.7 & $\mathrm{C}$ & 4.3 & 3.3 & 6.7 & $\mathrm{~N}$ \\
\hline & & & 2 & 6.7 & $\mathrm{C}$ & 4.3 & 5.3 & 6.7 & $\mathrm{~N}$ \\
\hline & & & 3.3 & 6.7 & $\mathrm{C}$ & & & & \\
\hline & & & 5.3 & 6.7 & B & & & & \\
\hline & & & 10.7 & 6.7 & B & & & & \\
\hline & & & \multicolumn{3}{|c|}{$\mathrm{E}_{\mathrm{T}} / \mathrm{E}_{\mathrm{Lt}}=0.8$ [14] } & & & & \\
\hline & & & 2.7 & 4 & $\mathrm{C}$ & & & & \\
\hline
\end{tabular}

841

842 